Article

\title{
Experimental Study on the Creep Characteristics of Coal Measures Sandstone under Seepage Action
}

\author{
Ziheng Sha ${ }^{1}{ }^{(1)}$, Hai Pu ${ }^{1,2, *}$, Ming $\mathrm{Li}^{1,3}{ }^{3}$, Lili Cao ${ }^{1}$, Ding Liu ${ }^{1}$, Hongyang $\mathrm{Ni}^{1}$ and Jingfeng Lu ${ }^{3}$ \\ 1 State Key Laboratory for Geomechanics and Deep Underground Engineering, \\ China University of Mining and Technology, Xuzhou 221116, China; \\ zhsha@cumt.edu.cn (Z.S.); mingl@cumt.edu.cn (M.L.); caolili429@126.com (L.C.); \\ liuding@cumt.edu.cn (D.L.); nhyang@cumt.edu.cn (H.N.) \\ 2 School of Mining Engineering, Xinjiang Institute of Engineering, Urumqi 830023, China \\ 3 School of Mechanics and Civil Engineering, China University of Mining and Technology, \\ Xuzhou 221116, China; jingfeng_lu@cumt.edu.cn \\ * Correspondence: haipu@cumt.edu.cn; Tel: +86-0516-8399-5398
}

Received: 28 June 2018; Accepted: 24 July 2018; Published: 1 August 2018

check for updates

\begin{abstract}
The seepage action of underground water accelerates the deformation of roadway surrounding rock in deep mines. Therefore, the study of creep characteristics of surrounding rock under seepage action is the basis for the stability control of roadway surrounding rock in deep water-rich areas. In this paper, a seepage-creep coupling test system for complete rock samples was established. Combined with a scanning electron microscopy (SEM) test system, the seepage-creep law of coal measures sandstone and the damage mechanism were revealed. The study results showed that the maximum creep deformation of sandstone under natural and saturation state decreased gradually with the increase of confining pressure, and the maximum creep deformation under saturation state was greater than the corresponding value under natural state when the confining pressure was same. When the confining pressure was constant, the creep deformation, the constant creep deformation rate and the accelerated creep deformation rate of sandstone increased rapidly with the increase of infiltration pressure. With the change of time, the change of permeability parameters went through three cycles; each cycle was divided into two stages, slow change stage and rapid change stage, and the rate of variation increased with the increase of the seepage pressure. Based on the macroscopic and microscopic characteristics of sandstone rupture, the connection between macroscopic and microscopic mechanism on sandstone rupture was established. The results in this paper can provide a theoretical basis for stability control of roadway surrounding rock in water-rich areas.
\end{abstract}

Keywords: coal measures sandstone; creep characteristics; seepage pressure; seepage-creep; microscopic morphology

\section{Introduction}

At present, many coal mines in China have entered the stage of deep mining. Compared with shallow coal mines, deep rock masses have significant rheological properties [1-7]. At the same time, the seepage action caused by underground water has also become one of the main factors which affect the stability control of roadway surrounding rock [8,9]. Especially in the process of deep mining, the creep characteristics of coal and rock medium under seepage are more pronounced. Therefore, to ensure the safety of deep mining, it is of great significance to understand the seepage-creep characteristics of rock thoroughly.

The study on rock creep properties originated from Griggs [10], who pointed out in 1939 that creep may occur when the load applied to the rock exceeds one-eighth of the damage load. 
Many studies [11,12] have shown that the rheological properties of rock are closely related to the complex stress conditions in which they are located. Maranini conducted uniaxial and triaxial compression creep tests on limestone and found that rock crack propagation under low confining pressure and pore collapse under high stress were the main causes of creep [13]. Fan carried out the triaxial compression creep tests of oil-bearing mudstone under low confining pressure; the results showed that there was an initial stress threshold of creep and failure stress threshold of creep [14]. Most of the laboratory tests on rock creep mainly focus on the study of compressive creep characteristics, but in fact, rock mass is often still in the complex stress conditions such as tension and shear. Therefore, some scholars [15-17] conducted researches on the creep characteristics of rock under different stress conditions. In recent years, many other scholars [18-24] have studied the rheological characteristics of rock from the microscopic level by using scanning electron microscopy (SEM) test system, CT (Computed Tomography) testing system and other equipment.

To study the seepage characteristics of fractured rock mass, many researchers have done a lot of work on seepage-stress coupling. Louis studied the seepage-stress relationship of a single fracture based on the results of fields water injection tests, and pointed out that the permeability coefficient of rock mass had a negative exponential relationship with normal stress [25]. Jones [26], Nelson [27], and Kranz [28] studied the permeability of different rocks respectively and established corresponding empirical formulas for permeability coefficients. Gale proposed an empirical formula which was similar to Cubic Law by conducting laboratory tests on three kinds of jointed rock masses [29]. Iwai found that the influence of joint roughness on the seepage law was mainly related to the contact rate of the fissure wall area [30]. Mordecai measured a $20 \%$ increase in permeability through a sandstone breaking test [31]. Li and Miao studied the seepage law and creep law of broken rock [32,33]. He conducted creep-seepage coupling tests on coal samples to reveal the consistency of permeability changes and the creep damage of coal samples [34]. Zhu studied the effect of seepage pressure on the damage and deterioration of brittle rock, and he also explored the change law of permeability characteristics during deformation process; the results showed that the seepage pressure had a certain degree of aggravating effect on the joint opening and expanded deformation of rock cracks [35]. Zhang conducted penetration tests on different rock samples and found that as the strain increases, the permeability increased more significantly [36]. Combined with damage mechanics model and numerical simulation tools, some researchers have also conducted some theoretical studies on seepage flow $[37,38]$. Based on the experimental results of rock stress-strain-permeability tests, Yang established a seepage-stress-damage coupling model with brittle characteristics from the microscopic view [39]. $\mathrm{Pu}$ studied the creep law of the overlying strata through a seepage-creep coupling model which was derived by himself [40]. Souley studied the relationship between excavation-disturbed zone of surrounding rock in an underground cavern and permeability through underground nuclear waste disposal tests in Canadian [41].

The creep test methods of rock have developed well. Relatively speaking, rock seepage-creep test technology is still in the development stage. Due to the low permeability of the complete rock samples, most of the studies used fractured rock or broken rock as the research object to carry out rock seepage tests or seepage-creep tests [42-44]. In recent years, some researchers $[8,45]$ have used self-made test systems to conduct seepage-creep test studies on complete rock samples. However, systematic research results are rare, because of the superior difficulty of such experiments. Therefore, in this paper, a rock seepage-creep coupling test system is built for the test requirements of complete rock samples. The creep tests under natural state and saturation state and the seepage-creep tests under different seepage pressures are carried out for the complete coal measures sandstone samples. The effects of seepage pressure on the creep properties of the rock and the whole process are investigated. This study provides a theoretical basis for the control of roadway surrounding rock in deep coal mines. 


\section{Materials and Methods}

\subsection{Material Characterization}

The rock samples were roof sandstone, taken from the overlying strata of a working face of a mine in Anhui. X-ray diffraction analysis was performed on the coal measures sandstone, and the mineral content of sandstones is shown in Table 1. It is observed that Kaolinite is a typical clay mineral and it is a binder between the internal material particles of the sandstone; when Kaolinite meets water, it will expand and soften. The feldspathic material is the main component of this type of sandstone, and its material particles will dilate and fracture under the long-term action of water, resulting in the macroscopic destruction of the rock [46].

According to the test plan, the sandstone was made into standard specimens $(\Phi \times h=50 \times 100 \mathrm{~mm})$ in accordance with the 'Test Procedures for the Physical and Mechanical Properties of Rocks', and the machining accuracy of the specimens should meet the requirements of 'Standard for Test Method of Engineering Rock Mass' (GB50218-94) (Figure 1). The physical and mechanical properties of sandstone were tested, and its basic physical and mechanical parameters were obtained (Table 2). It is worth noting that all the parameters in Table 2 were obtained by taking the average of the results of multiple tests. Before the seepage-creep coupling test, the finished specimens were placed in water under a room temperature $\left(20^{\circ} \mathrm{C}\right)$ until the weight of the specimens no longer changed, then the specimens were considered saturated.

Table 1. Mineral content of sandstones.

\begin{tabular}{cccc}
\hline Anorthite-Ca( $\left.\mathrm{Al}_{2} \mathrm{Si}_{2} \mathrm{O}_{8}\right)$ & Microcline Maximum-K(AlSi $\left.{ }_{3}\right) \mathbf{O}_{8}$ & Kaolinite- $\mathbf{A l}_{2} \mathbf{S i}_{2} \mathbf{O}_{5}(\mathbf{O H})_{4}$ & Quartz-SiO \\
\hline $45.2 \%$ & $31.4 \%$ & $13.8 \%$ & $9.6 \%$ \\
\hline
\end{tabular}

Table 2. Basic physical and mechanical properties of sandstones.

\begin{tabular}{cccccccc}
\hline$\rho /\left(\mathbf{k g} \cdot \mathbf{m}^{-3}\right)$ & $v /\left(\mathbf{m} \cdot \mathbf{s}^{-1}\right)$ & $E / \mathrm{GPa}$ & $\mu$ & $\sigma_{\mathbf{u}} / \mathbf{M P a}$ & $\sigma_{\mathrm{T}} / \mathbf{M P a}$ & $\sigma_{\mathrm{t}} / \mathbf{M P a}$ & $\varphi^{\circ}$ \\
\hline 2540 & 2650 & 37.65 & 0.26 & 122.45 & 149.29 & 2.85 & 38 \\
\hline
\end{tabular}

Remarks: $\rho$, density; $v$, longitudinal wave velocity; $E$, elasticity modulus; $\mu$, Poisson's ratio; $\sigma_{\mathrm{u}}$, uniaxial compression strength; $\sigma_{\mathrm{T}}$, triaxial compression strength (confining pressure is $3 \mathrm{MPa}$ ); $\sigma_{\mathrm{t}}$, tensile strength; $\varphi$, the angle of internal friction.

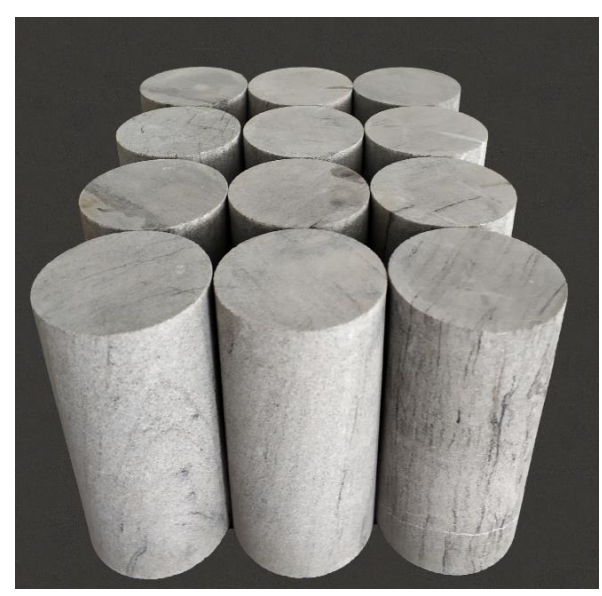

Figure 1. Part of finished samples.

\subsection{Testing System}

To meet the requirements of seepage-creep coupling tests for intact rock specimens, the existing equipment and devices were used to design and set up a rock seepage-creep coupling test system for 
standard rock specimens. The entire system consists of five parts: the axial pressure loading system, the confining pressure loading system, the seepage pressure loading system, the rock seepage system, and the data collecting and processing system, as shown in Figure 2.

1. The axial pressure loading system uses the Electro-hydraulic servo rock mechanics test system of MTS816 to provide a stable and continuous axial load for the specimen during the test, as shown in Figure 2a.

2. The confining pressure loading system applies a certain pressure to the specimen by using the pump to press the hydraulic oil into the cylinder.

3. The seepage pressure loading system provides a continuous and stable seepage pressure for the specimen based on the injector concept, and this is an important part to achieve the seepage-creep coupling effect, as shown in Figure $2 b$.

4. The rock seepage system is the core part of the rock seepage-creep coupling test system. It is the central system of the axial loading system, confining pressure loading system and seepage pressure loading system. Figure 2c shows the structural compositions of the rock seepage system. As can be seen from the picture, the entire testing system is roughly composed of 14 parts.

5. The data collecting and processing system includes a paperless recorder, a pressure transmitter, a flow sensor, and a computer terminal.

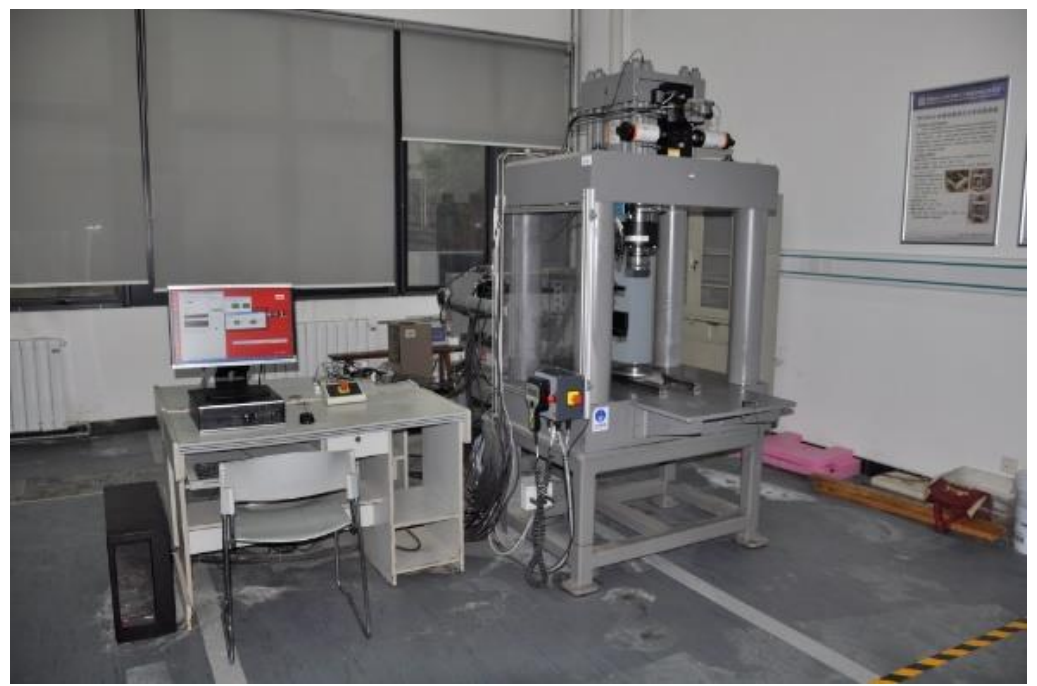

(a) Electro-hydraulic servo rock mechanics test system of MTS816.
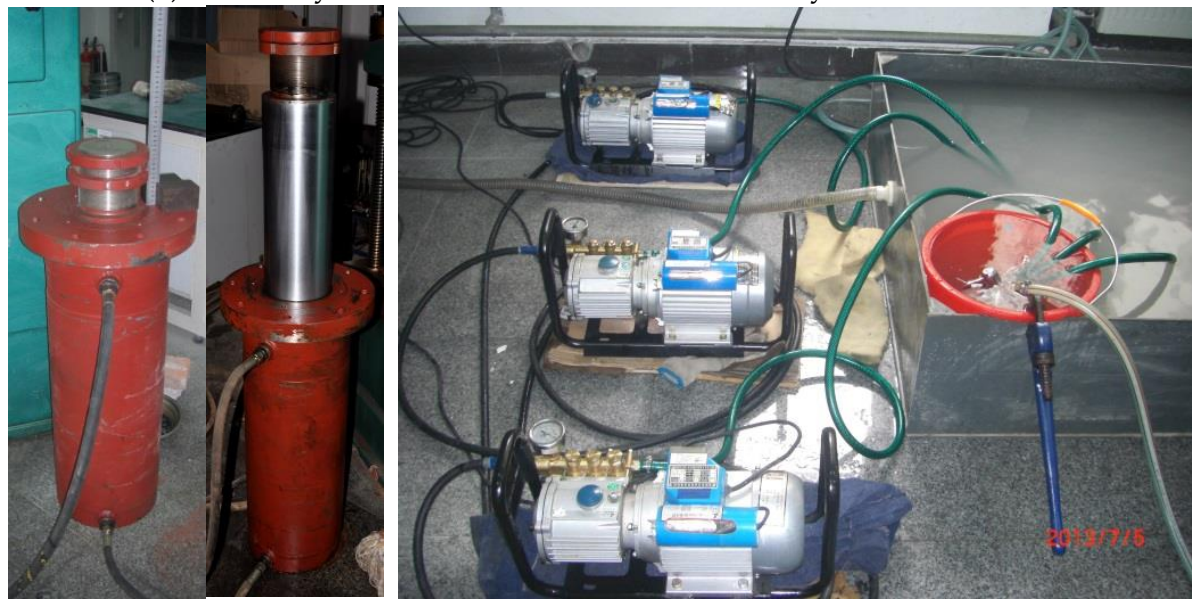

(b) Equipment of seepage pressure loading system.

Figure 2. Cont. 

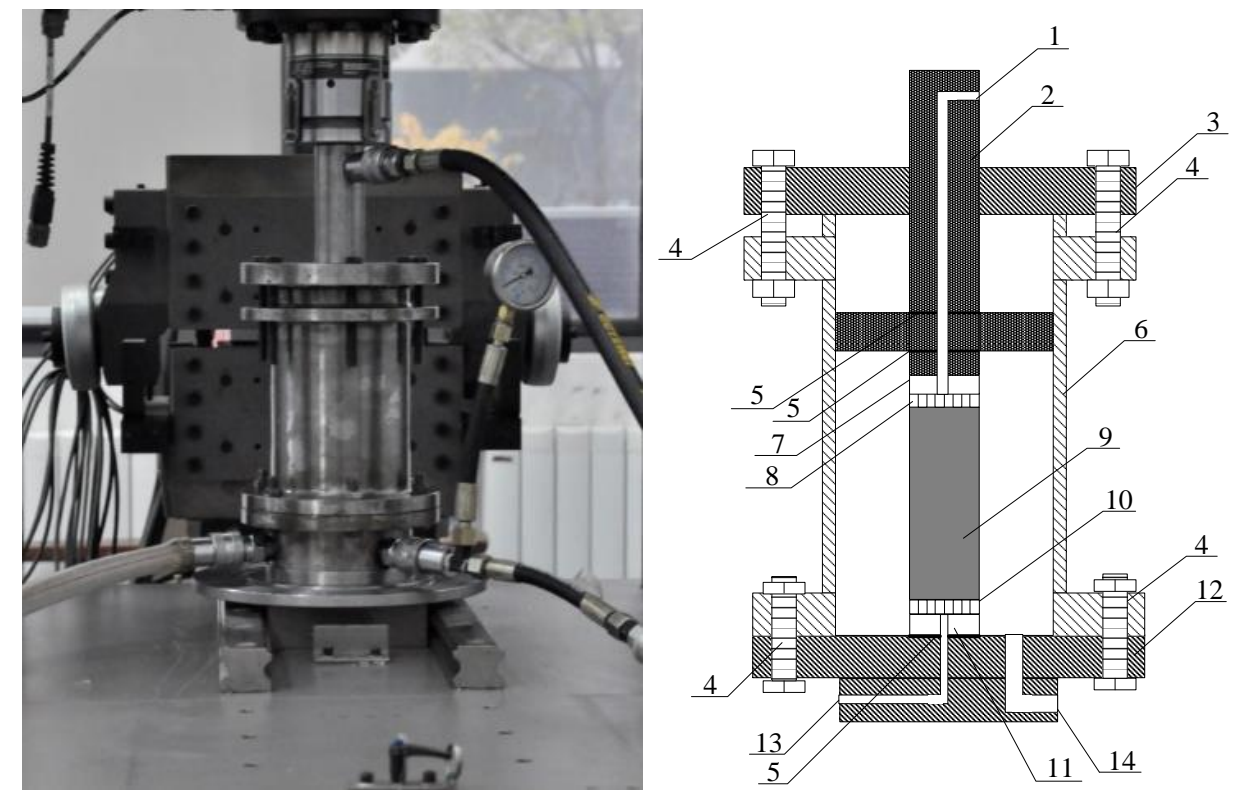

1-water injection hole; 2 -piston; 3-head cover; 4-high Strength bolt; 5-O-type sealing ring; 6cylinder block; 7-universal joint; 8-overlying porous disc; 9-rock sample; 10-lower porous disc; 11-pedestal; 12 -baseplate with holes; 13 -water outlet; 14 -entrance of hydraulic oil

(c) Rock seepage system and its structure composition.

Figure 2. Rock seepage-creep coupling test system.

\subsection{Test Scheme}

The creep test adopts the method of gradation loading by applying different stress levels to the same rock specimens step by step. The final creep deformation of a specimen is the superposition of the creep deformation under each stage of load.

By using the rock seepage-creep coupling test system, the creep tests of coal measures sandstone under different seepage pressures will be tested. The specific experimental scheme is as follows (Figure 3):

1. Triaxial compression tests of sandstone. Triaxial tests of sandstone will be carried out under the natural state and the saturation state and the confining pressures are $1 \mathrm{MPa}, 2 \mathrm{MPa}, 3 \mathrm{MPa}$, and $4 \mathrm{MPa}$. Then the compressive strengths of sandstone under four confining pressures in two states are determined. According to the triaxial compressive strength, the load classification scheme of sandstone creep experiment can be obtained.

2. Triaxial creep tests of sandstone. According to the different loading levels, the creep tests with confining pressures of $1 \mathrm{MPa}, 2 \mathrm{MPa}, 3 \mathrm{MPa}$, and $4 \mathrm{MPa}$ are carried out under natural and saturation conditions respectively, and the creep characteristics of sandstone under two conditions are obtained finally.

3. Seepage-creep coupling tests of sandstone. Water saturated rock specimens are used as the targets to perform the rock creep tests under different seepage pressures. The confining pressure is $4 \mathrm{MPa}$, and the seepage pressure $p_{0}$ is $0.5 \mathrm{MPa}, 1.5 \mathrm{MPa}, 2.5 \mathrm{MPa}$, and $3.5 \mathrm{MPa}$. The effect of seepage pressure on the creep deformation and permeability of sandstone can be obtained. 


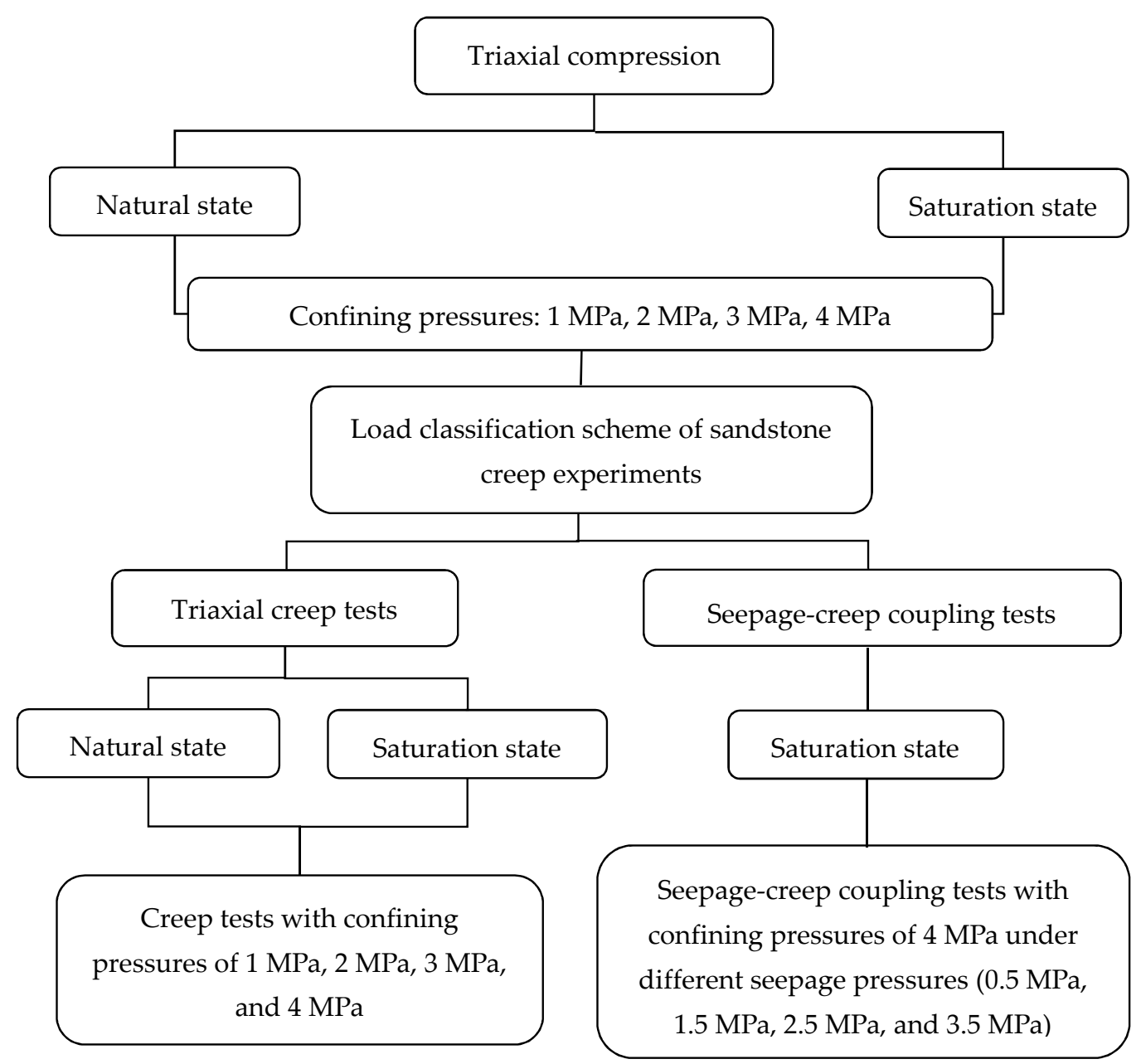

Figure 3. Test scheme.

\subsection{Load Grading}

Firstly, the triaxial compression tests of sandstones in natural and saturated conditions under different confining pressures $(p=1 \sim 4 \mathrm{MPa}$ ) were carried out. Figure 4 shows the variation of triaxial compression strength with confining pressure under two conditions. With the increase of confining pressure, the peak strength of sandstone under two states all increases linearly. When the confining pressure increases from $1 \mathrm{MPa}$ to $4 \mathrm{MPa}$, the peak strength of sandstone in natural state increases from $128.69 \mathrm{MPa}$ to $158.74 \mathrm{MPa}$, and the increase amplitude is $23.35 \%$. Under the saturation condition, the peak strength of sandstone increases from $69.01 \mathrm{MPa}$ to $115.26 \mathrm{MPa}$, and the increase amplitude is $67.02 \%$. Comparing the two sets of curves, under the same confining pressure conditions, the peak strength of natural sandstone is greater than the peak strength of sandstone under the saturation condition, and the difference value between them is in the range of $42.54 \sim 59.68 \mathrm{MPa}$. The slope of the peak intensity change curve of sandstone under the saturation state is greater than that of the curve under the natural state, which indicates that the peak intensity of sandstone under the saturation condition is more sensitive to the confining pressure. 


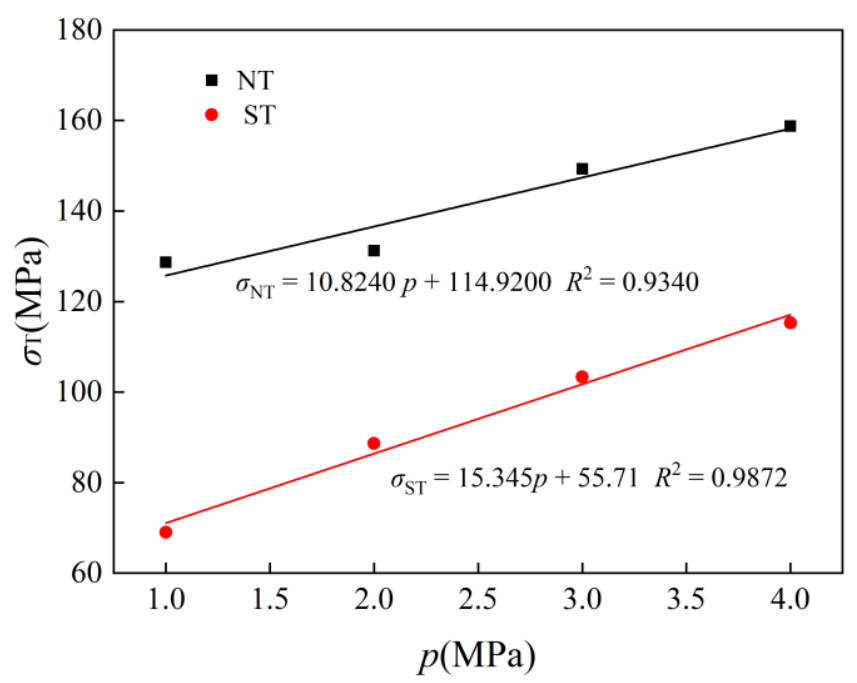

Figure 4. Change of maximum stress of sandstone with confining pressure.

According to the load classification principle of creep tests, combined with the results of the triaxial tests, the maximum stress is $90 \%$ of the peak strength, and then 6 equal parts are used to determine the graded loadings. The loading time $t$ of each level is $4 \mathrm{~h}$; if the rock specimen does not break down finally, the load will increase to the peak stress to continue the test. Table 3 shows the specific load classification scheme.

Table 3. Load classification scheme of sandstone creep experiment.

\begin{tabular}{|c|c|c|c|c|c|c|c|c|}
\hline \multirow{2}{*}{$\begin{array}{l}\text { Hierarchical } \\
\text { Load }\end{array}$} & \multicolumn{4}{|c|}{ Natural Condition } & \multicolumn{4}{|c|}{ Saturation Condition } \\
\hline & $p=1 \mathrm{MPa}$ & $p=2 \mathrm{MPa}$ & $p=3 \mathrm{MPa}$ & $p=4 \mathrm{MPa}$ & $p=1 \mathrm{MPa}$ & $p=2 \mathrm{MPa}$ & $p=3 \mathrm{MPa}$ & $p=4 \mathrm{MPa}$ \\
\hline$\sigma_{1}(\mathrm{MPa})$ & 20 & 20 & 23 & 25 & 10 & 14 & 15 & 18 \\
\hline$\sigma_{2}(\mathrm{MPa})$ & 40 & 40 & 46 & 50 & 20 & 28 & 30 & 36 \\
\hline$\sigma_{3}(\mathrm{MPa})$ & 60 & 60 & 69 & 75 & 30 & 42 & 45 & 54 \\
\hline$\sigma_{4}(\mathrm{MPa})$ & 80 & 80 & 92 & 100 & 40 & 56 & 60 & 72 \\
\hline$\sigma_{5}(\mathrm{MPa})$ & 100 & 100 & 115 & 125 & 50 & 70 & 75 & 90 \\
\hline$\sigma_{6}(\mathrm{MPa})$ & 120 & 120 & 138 & 150 & 60 & 84 & 90 & 108 \\
\hline
\end{tabular}

\subsection{The Method of Microscopic Damage Test}

\section{(1) Test Equipment}

The SEM technique was used to observe the fracture morphology of the damaged sandstone specimens. The equipment we used was a TESCAN VEGA3 (TESCAN, Brno, Czech Republic) type scanning electron microscope system, as shown in Figure 5. The principle of SEM test is to scan the surface of the specimens by using an electron beam emitted by the electron gun. Then specimens need to be excited to produce various physical signals. After detection, video amplification and signal processing, scanned images that can reflect various features of the specimen surface can be obtained on the viewing screen. 


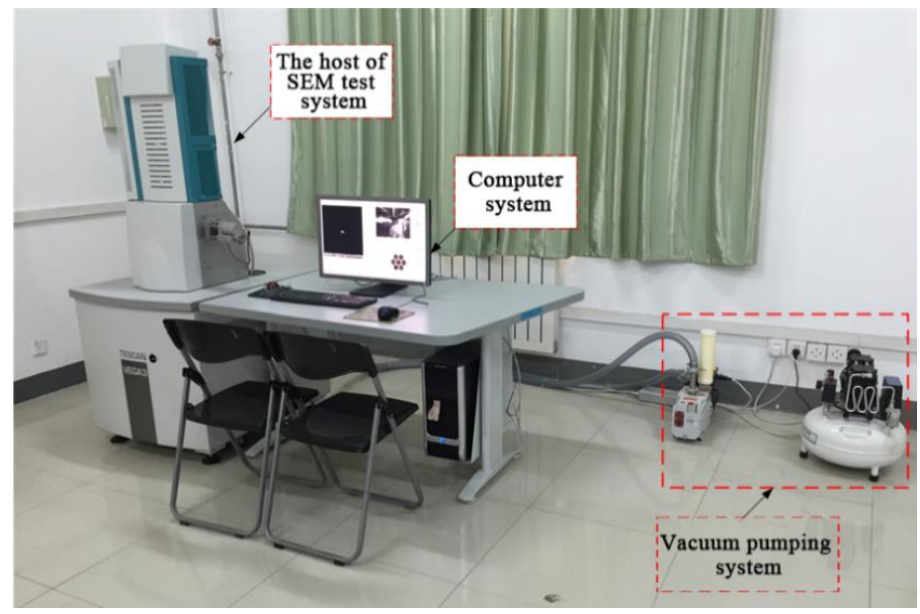

Figure 5. Scanning electron microscopy (SEM) test system.

\section{(2) Sample Preparation}

First, we picked out the sample fragments that have flat surface after destruction, and then selected the appropriate size $(\Phi \times h=10 \times 2 \mathrm{~mm})$ fragments from the middle of the sample rupture surfaces as the observation samples. The lower surfaces (non-observed surface) of the observation specimens need to be sanded with sandpaper to ensure that the specimens can be fixed on the sample platform steadily. Next, we needed to clean the observation surfaces by using a special equipment and then attached the observation samples to the sample platform. Finally, the surfaces of the observation samples were sputtered by an SBC-12 (KYKY Technology Co., Ltd., Beijing, China) ion sputtering equipment and then the sample preparation was completed (Figure 6).

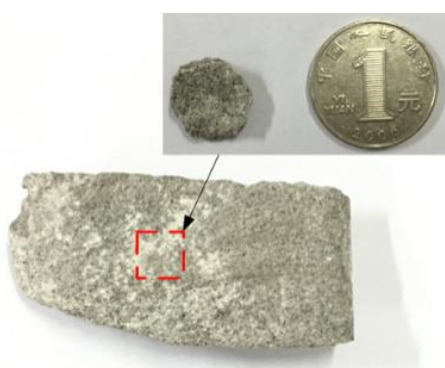

(a) Sample selection

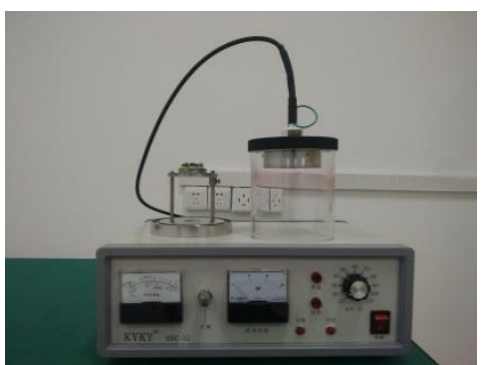

(b) SBC-12 ion sputtering equipment

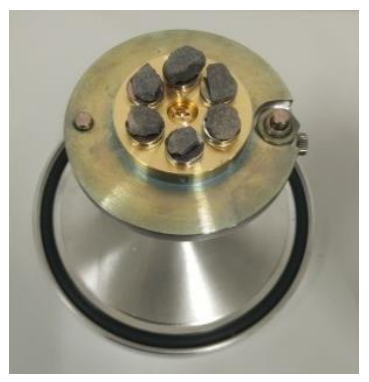

(c) Finished samples

Figure 6. Observe sample preparation

\section{Results and Discussion}

\subsection{Creep Properties of Sandstone under Natural State and Saturation State}

\subsubsection{Creep Deformation Law of Sandstone under Two States}

According to the test scheme, the creep tests of sandstone under natural and saturation conditions were carried out respectively, and the strain-time curves of sandstone under different confining pressures were obtained too. Finally, according to the principle of graded loading, the creep curves of sandstone were obtained, as shown in Figures 7 and 8.

As can be seen from Figures 7 and 8, the creep characteristic curves of sandstone all show a stepwise upward trend. Under each load, sandstone undergoes instantaneous deformation and stable deformation (or accelerated deformation under high loads), and more than $90 \%$ of the final deformation occurs instantaneously. 


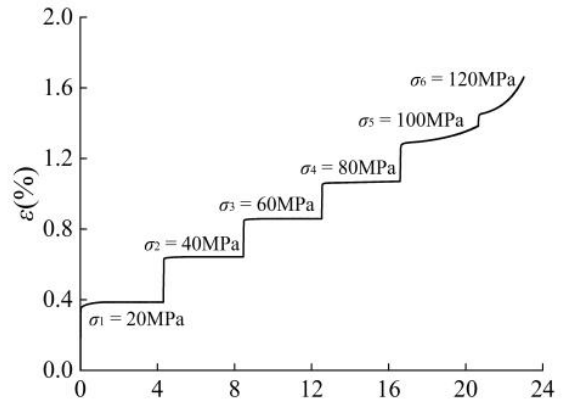

$t(\mathrm{~h})$

(i) Strain-time curve $(\varepsilon-t)$

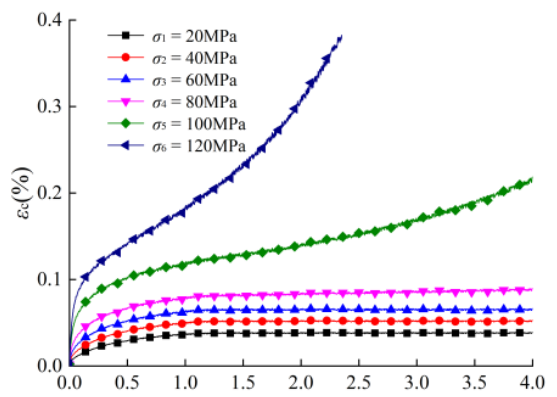

$t$ (h)

(ii) Creep deformation curve $\left(\varepsilon_{\mathrm{c}}-t\right)$

(a) $p=1 \mathrm{MPa}$

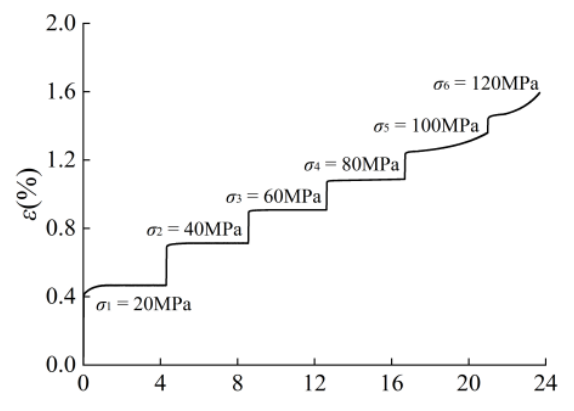

$t(\mathrm{~h})$

(i) Strain-time curve $(\varepsilon-t)$

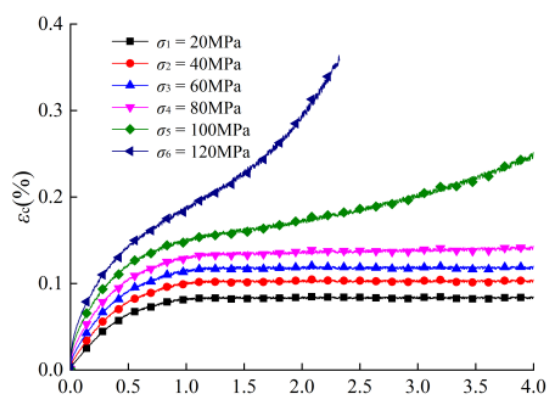

$t$ (h)

(ii) Creep deformation curve $\left(\varepsilon_{\mathrm{c}}-t\right)$

(b) $p=2 \mathrm{MPa}$

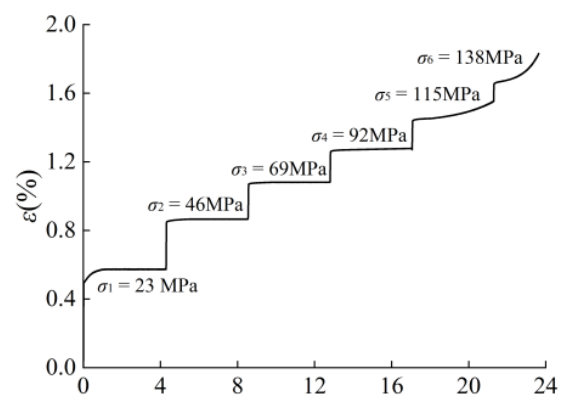

$t(\mathrm{~h})$

(i) Strain-time curve $(\varepsilon-t)$

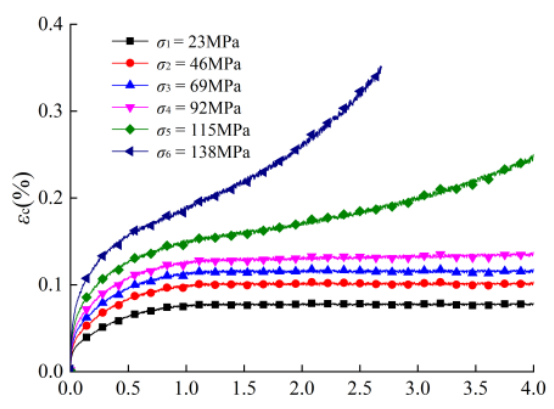

$t$ (h)

(ii) Creep deformation curve $\left(\varepsilon_{\mathrm{c}}-t\right)$

(c) $p=3 \mathrm{MPa}$

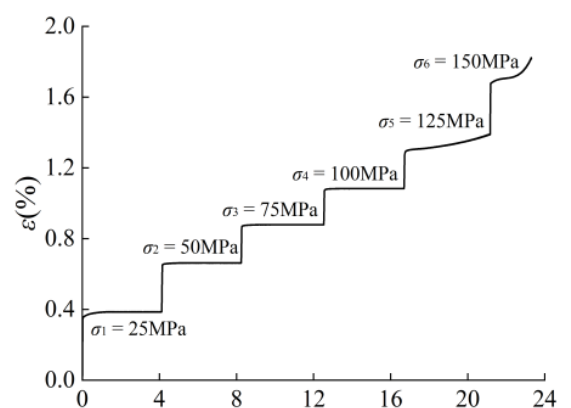

$t(\mathrm{~h})$

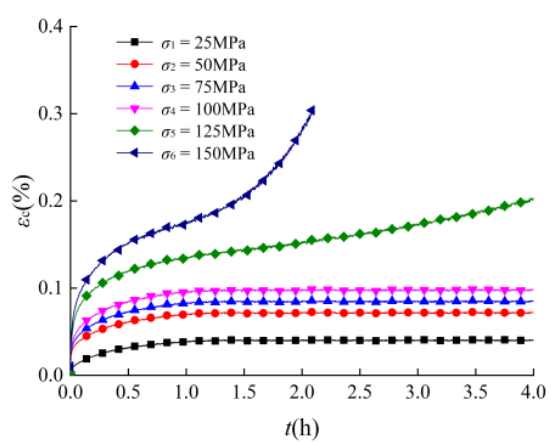

(ii) Creep deformation curve $\left(\varepsilon_{\mathrm{c}}-t\right)$

(i) Strain-time curve $(\varepsilon-t)$

(d) $p=4 \mathrm{MPa}$

Figure 7. Creep characteristic curves of sandstone in natural condition. 


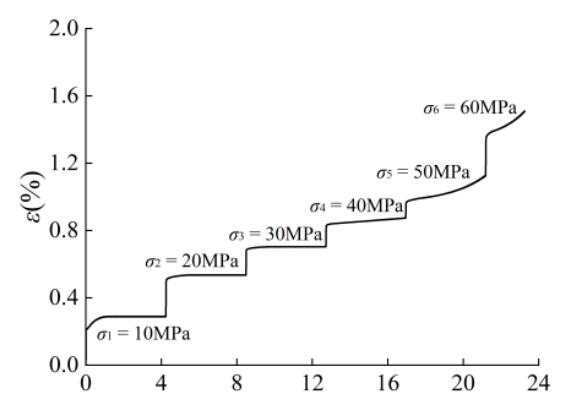

$t$ (h)

(i) Strain-time curve $(\varepsilon-t)$

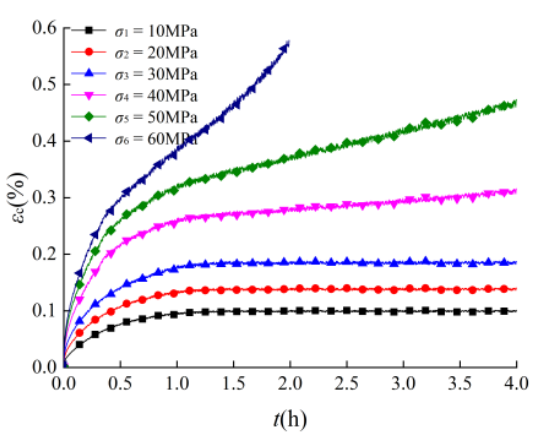

(ii) Creep deformation curve $\left(\varepsilon_{\mathrm{c}}-t\right)$

(a) $p=1 \mathrm{MPa}$

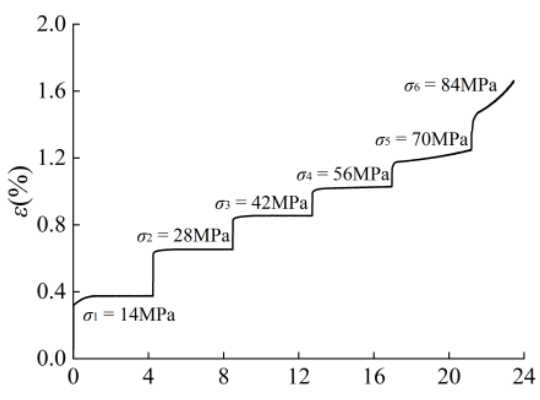

$t$ (h)

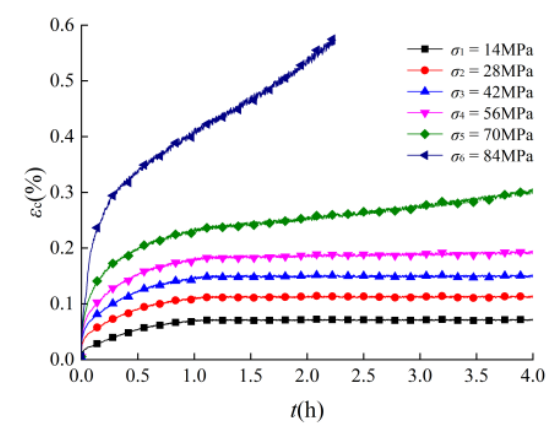

(ii) Creep deformation curve $\left(\varepsilon_{\mathrm{c}}-t\right)$

(i) Strain-time curve $(\varepsilon-t)$ (b) $p=2 \mathrm{MPa}$

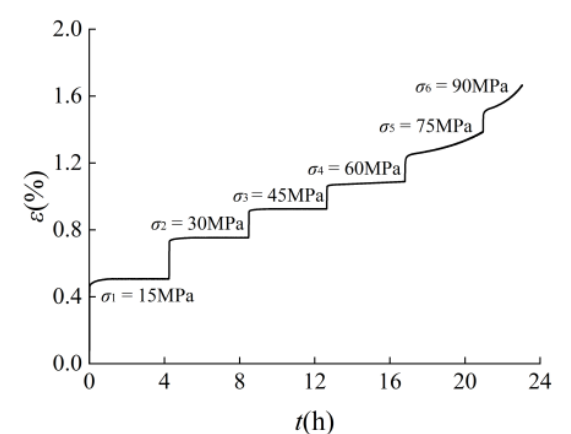

(i) Strain-time curve $(\varepsilon-t)$

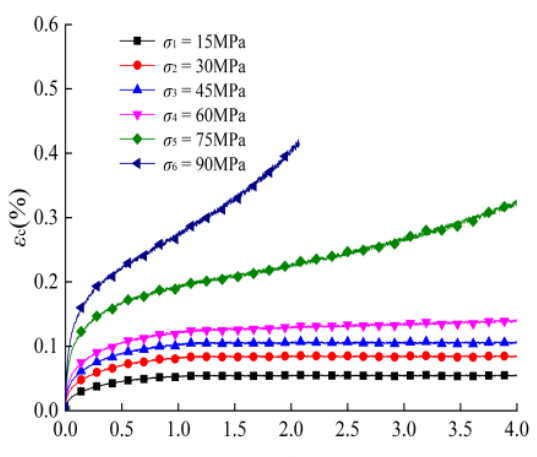

$t(\mathrm{~h})$

(ii) Creep deformation curve $\left(\varepsilon_{\mathrm{c}}-t\right)$

(c) $p=3 \mathrm{MPa}$

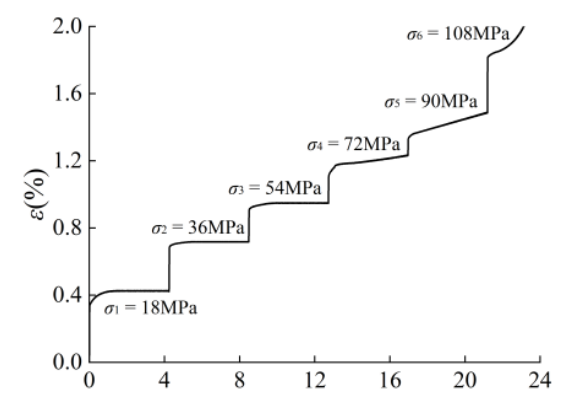

$t$ (h)

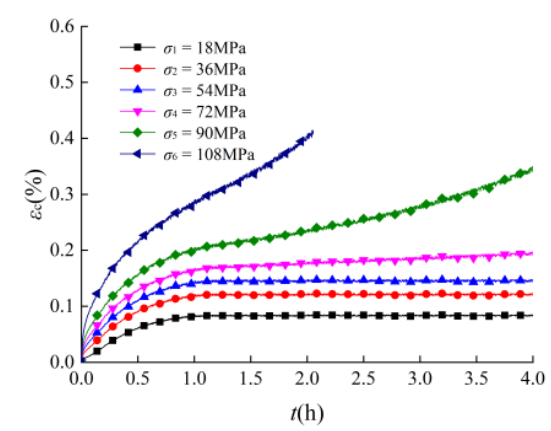

(ii) Creep deformation curve $\left(\varepsilon_{\mathrm{c}}-t\right)$

(i) Strain-time curve $(\varepsilon-t)$ (d) $p=4 \mathrm{MPa}$

Figure 8. Creep characteristic curves of sandstone in saturation condition. 
Figure 9 shows that when the confining pressure increases from $1 \mathrm{MPa}$ to $4 \mathrm{MPa}$, the final strain of natural and saturated sandstone increases from $1.66 \%$ and $1.51 \%$ to $1.82 \%$ and $2.01 \%$, respectively. With the increase of confining pressure, the final deformation of sandstone gradually increases, which is mainly determined by the graded loads, because the graded load develops with the confining pressure, resulting in greater deformation of sandstone. Under the same axial pressure conditions, the greater the confining pressure, the smaller the final deformation of the sandstone.

Comparing with the creep characteristic curves, the confining pressure increases from $1 \mathrm{MPa}$ to $4 \mathrm{MPa}$, and the final creep strain of natural and saturated sandstones decreases from $0.38 \%$ and $0.58 \%$ to $0.30 \%$ and $0.41 \%$, respectively. The final deformation of sandstone gradually decreases with the increase of confining pressure, as shown in Figure 10. Comparing the maximum creep deformation curves of sandstone under two conditions, we can see that under the same confining pressure condition, the final creep deformation of sandstone under saturation state is greater than the corresponding value under natural state, which reflects the physical erosion and softening effect of water on the sandstone.

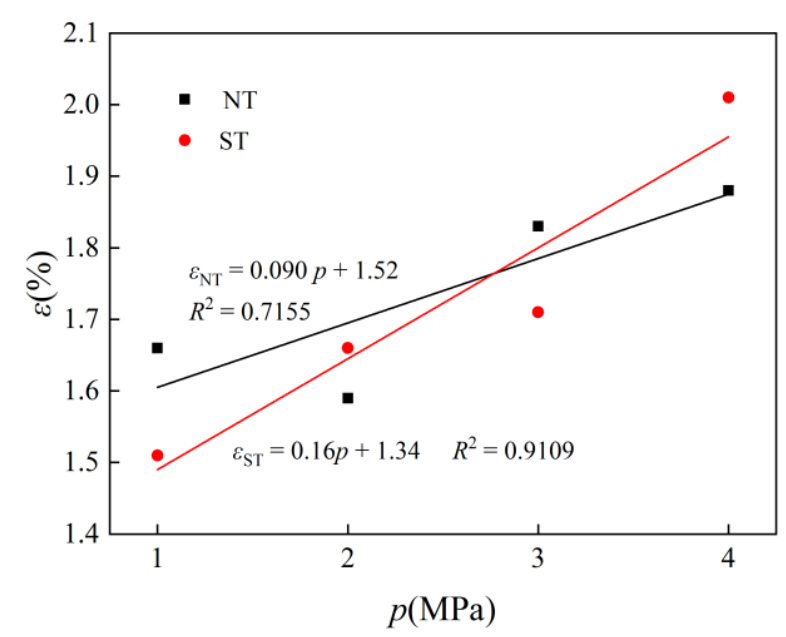

Figure 9. Change of the maximum deformation of sandstone.

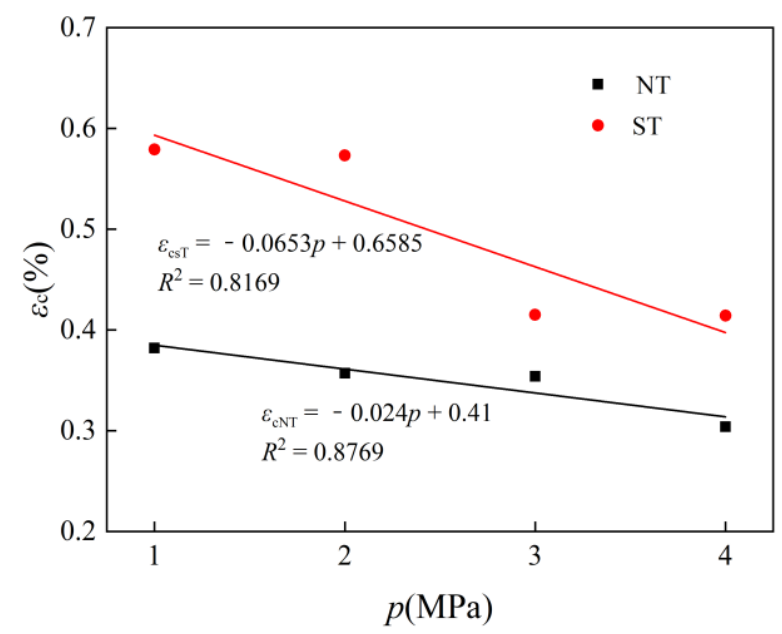

Figure 10. Change of the maximum creep deformation of sandstone.

\subsubsection{Creep Deformation Rate of Sandstone under Two States}

Deformation rate is an important indicator to reflect the creep deformation characteristics of sandstone. The deformation rate of stable creep and accelerated creep (which means the slopes of the creep characteristic curves) of sandstone under level 5 load and level 6 load are studied. Figure 11 shows the variation law of the slope of stable creep and accelerated creep deformation curves of 
sandstone under two states with confining pressure when the rock samples are under level 5 load and level 6 load. The effect of confining pressure on the creep deformation rate of sandstone is significant, but the characteristics of their deformation rates are different under different load levels. Under the level 5 load, the creep deformation rate of sandstone increases with the confining pressure, while the slope of the curve of the creep deformation rate of sandstone under the saturation condition is greater. Under the level 6 load, the stable creep and accelerated creep deformation rates of sandstone decrease with the increase of confining pressure.

The variation law of creep deformation rate of sandstone with confining pressure under different loading levels shows that: under the level 5 load, the creep deformation rate of sandstone is mainly affected by the load size, while the creep deformation rate is mainly affected by the confining pressure under the level 6 load. The cause of this phenomenon is that the confining pressure is an important factor to prevent the axial deformation of the rock. Under the same load, the larger the confining pressure is, the smaller the deformation rate and deformation of the rock are. In addition, the greater the axial pressure is, the greater the deformation rate is, indicating that the axial load plays an important role in the creep deformation of sandstone. Also, the larger the confining pressure is, the smaller the deformation rate is, which indicates that the effect of confining pressure on creep deformation is more significant.

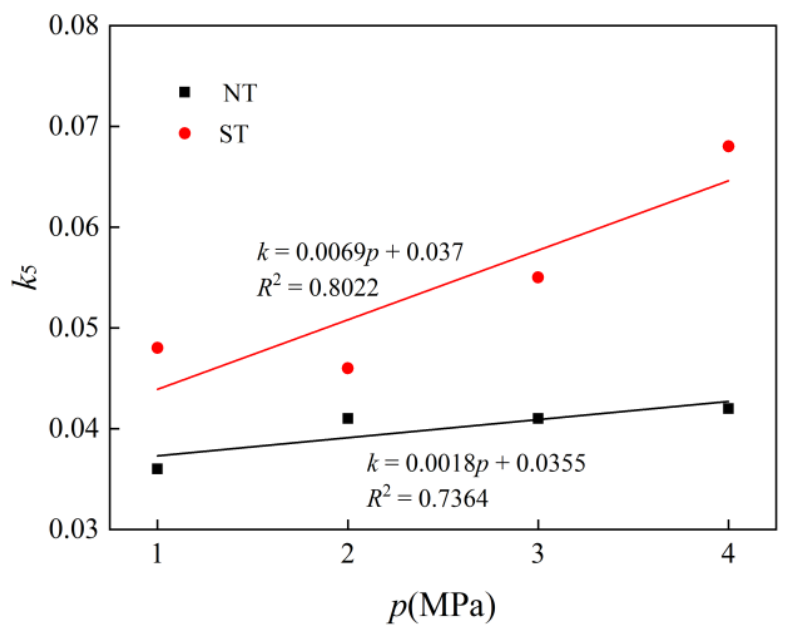

(a) Isokinetic creep deformation rate under level 5 load

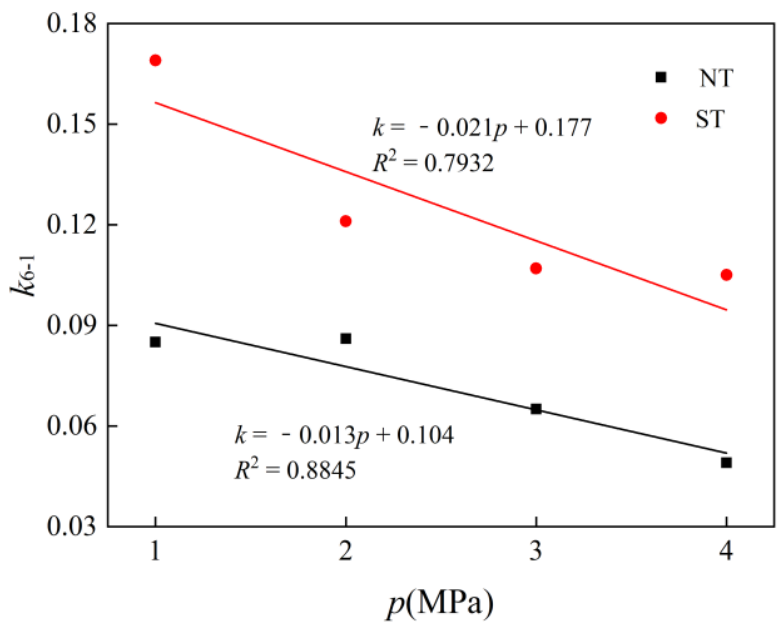

(b) Isokinetic creep deformation rate under level 6 load

Figure 11. Cont. 


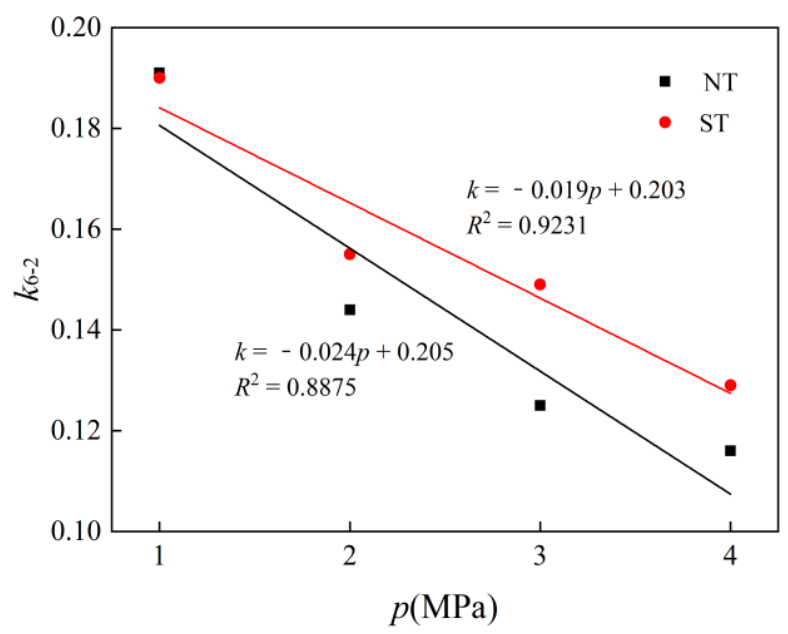

(c) Accelerated creep deformation rate under level 6 load

Figure 11. Change of creep deformation rate of sandstone.

\subsection{Influence of Seepage Pressure on Seepage-Creep Properties of Sandstone}

\subsubsection{Variation of Creep Deformation of Sandstone with Seepage Pressure}

Under the confining pressure of $4 \mathrm{MPa}$, creep tests of sandstone under the action of seepage pressures of $0.5 \mathrm{MPa}, 1.5 \mathrm{MPa}, 2.5 \mathrm{MPa}$ and $3.5 \mathrm{MPa}$ were carried out respectively, and the strain-time curves of sandstone were obtained, as shown in Figure 12. The curve with the seepage pressure of $0 \mathrm{MPa}$ refers to the creep characteristic curve of the sandstone in the saturation state under no seepage pressure. The creep curves of sandstone show a stepwise upward trend, and the shape of each curve is basically the same.

Figure 13 shows the creep curves of sandstone under different seepage pressures. As can be seen from the whole curves, as the seepage pressure increases, the instantaneous deformation of sandstone under the same loading level increases gradually. Compared with the other four groups of curves, when the seepage pressure is $3.5 \mathrm{MPa}$, accelerated deformation and failure will occur under the level 5 load. With the increase of seepage pressure, the final deformation and maximum creep deformation of sandstone increase gradually, and the slopes of stable creep stage and accelerated creep stage change significantly.

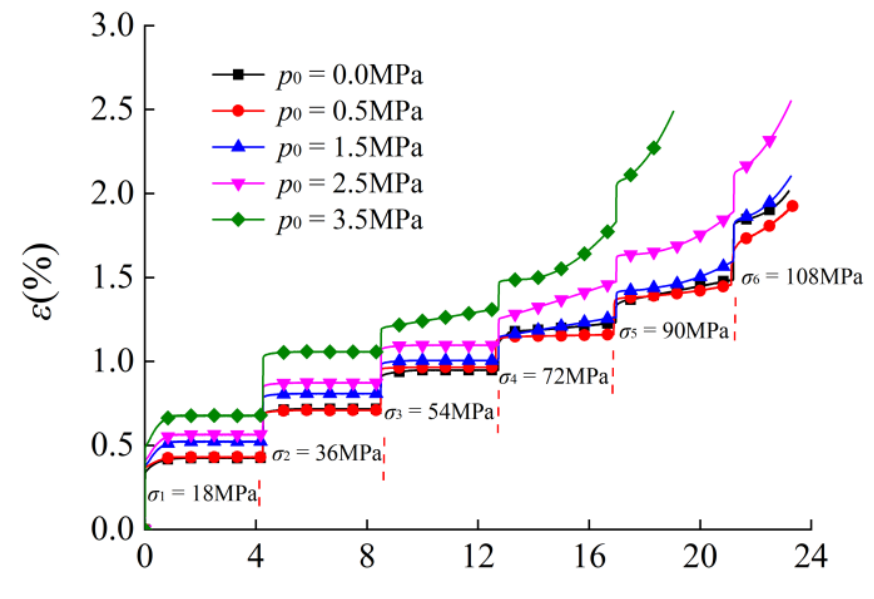

$t(\mathrm{~h})$

Figure 12. Seepage-creep strain-time curve of sandstone under difference seepage pressures. 


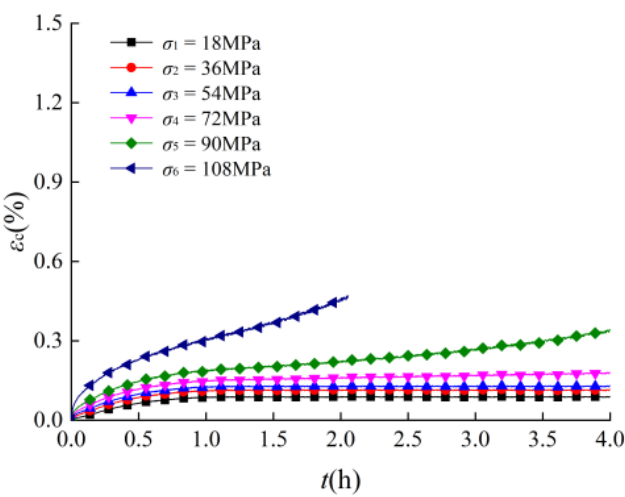

(a) $p_{0}=0.5 \mathrm{MPa}$

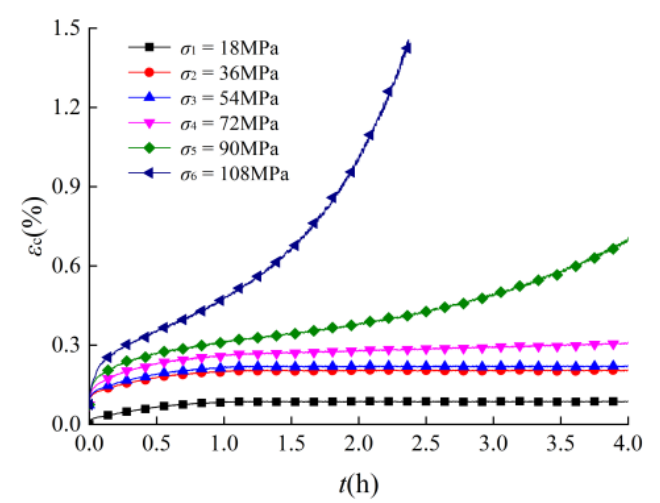

(c) $p_{0}=2.5 \mathrm{MPa}$

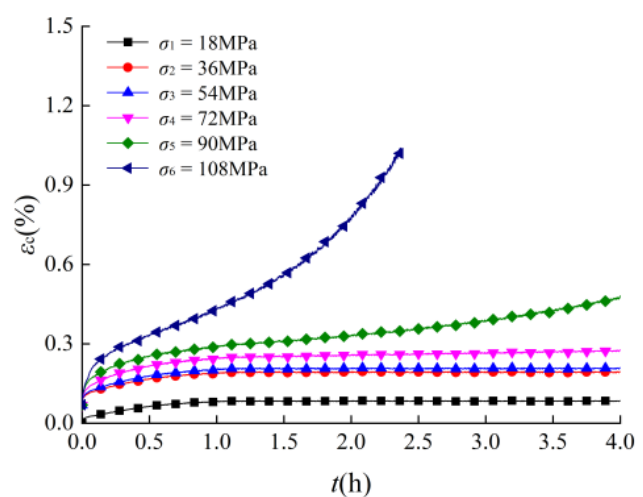

(b) $p_{0}=1.5 \mathrm{MPa}$

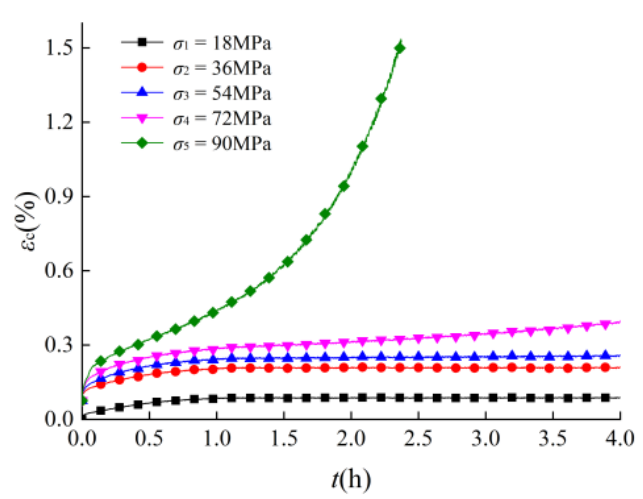

(d) $p_{0}=3.5 \mathrm{MPa}$

Figure 13. Seepage-creep deformation curve of sandstone under difference seepage pressures.

According to the creep characteristic curves, the curve of maximum deformation and maximum creep deformation of sandstone with seepage pressure was obtained, as shown in Figure 14. With the increase of the seepage pressure, the final deformation of the sandstone and the maximum creep deformation increase approximately linearly. It should be noted that the sandstone has been destroyed under the seepage pressure of $3.5 \mathrm{MPa}$ at level 5 load; therefore, the maximum deformation is slightly reduced.

The slope of the creep deformation curve of the sandstone under the last two loading levels was studied. From Figure 15, it can be seen that, as the seepage pressure increases, the slope of each creep curve gradually increases, indicating that the creep deformation rate of sandstone increases steadily. The seepage pressure has three types of effects on the creep deformation of rock: First, the seepage pressure can directly act on the sandstone in the form of axial pressure. Under the same confining pressure, the greater the axial pressure, the greater the deformation and deformation rate of sandstone. Second, the seepage pressure can provide an extended pressure on the internal crack tip of the sandstone. The greater the seepage pressure is, the faster the crack tip develops, and the sandstone deformation and deformation rate increase correspondingly. In addition, the seepage pressure can produce a certain scouring effect on the crack surface. The greater the seepage pressure, the greater the corresponding scouring effect, resulting in a smaller surface roughness of the crack. As a result, it is easier to slide on both sides of the crack, and the macroscopic performance is that the deformation rate of sandstone gradually increases. 


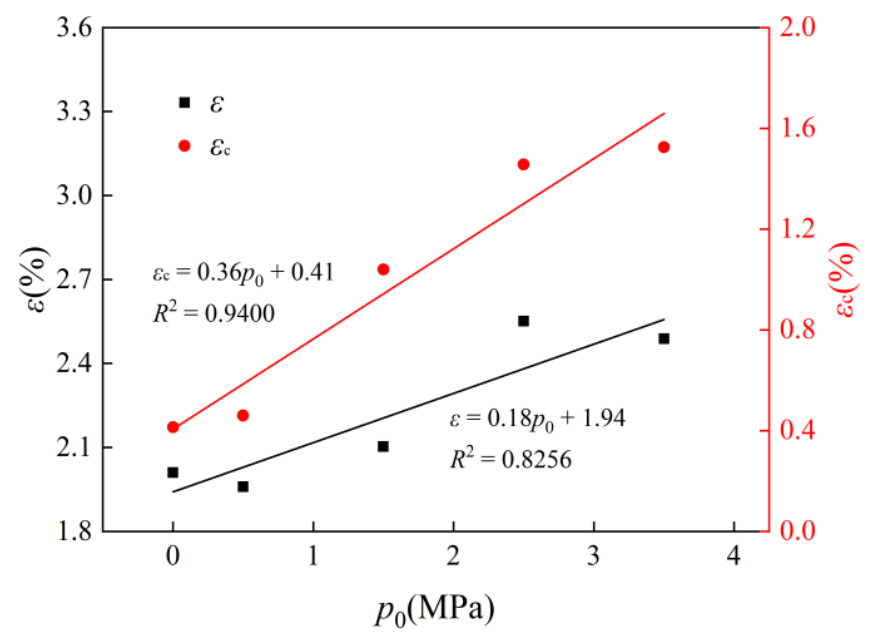

Figure 14. Change of maximum deformation of sandstone with seepage pressure.

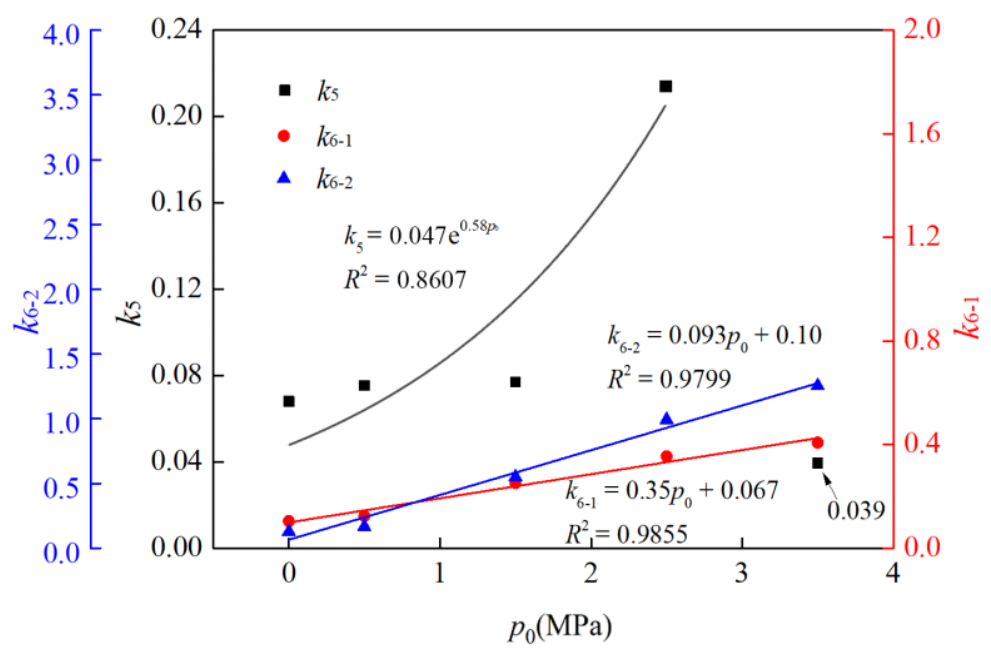

Figure 15. Change of creep slope of sandstone with seepage pressure.

\subsubsection{Variation of Seepage Properties of Sandstone with Seepage Pressure}

Figure 16 shows the curve of the permeability and the rate of permeability of sandstone with time under different seepage pressures during the tests; Figure 17 shows the curves of the permeability parameters of sandstone with time.

From Figure 17, it can be seen that the permeability parameters of sandstone undergo three cycles of change over time. In each cycle, the permeability parameters of sandstone gradually increase with time. At the junction of two cycles, these permeability parameters all drop rapidly. This change trend is the same as the change of permeability in Figure 16. On the other hand, the change of permeability of sandstone under different seepage pressures is particularly significant in the vertical dimension.

The time when the permeability parameters were measured for the first time during the tests shows a gradual advancement as the seepage pressure increases. In particular, under the seepage pressure of $3.5 \mathrm{MPa}$, the corresponding permeability parameters can be measured at the level 3 load ( $54 \mathrm{MPa})$, which the time is $8.42 \mathrm{~h}$. In addition, under the other seepage pressures, the permeability parameters were measured at the level 4 load $(72 \mathrm{MPa})$ for the first time through the tests. The specific moments are $12.08 \mathrm{~h}\left(p_{0}=2.5 \mathrm{MPa}\right), 13.58 \mathrm{~h}\left(p_{0}=1.5 \mathrm{MPa}\right)$, and $15.50 \mathrm{~h}\left(p_{0}=0.5 \mathrm{MPa}\right)$, respectively. In the process of the tests, the change of the permeability characteristics is reflected by the change of the permeable capacity, and the time for the first measurement of the permeable capacity is different, 
which indicates that the time for the first appearance of the permeable channel in the sandstone is different. To be more specific, with the increase of the seepage pressure, the time for the appearance of permeable channels within the sandstone becomes faster. Comparing with the creep deformation curves, stable creep and decelerating creep all occur during the deformation stages that can measure the permeability of water. Therefore, sandstone had already experienced stable creep at the first measurement of permeable capacity, which can be reflected in the creep deformation curves.

Within each variation period, the maximum permeability parameters of sandstone increase with the increase of the seepage pressure. At the end of each loading cycle, the permeability of the permeable channels in the sandstone increases with the increase of the seepage pressure, and the internal cracks develop more abundantly.

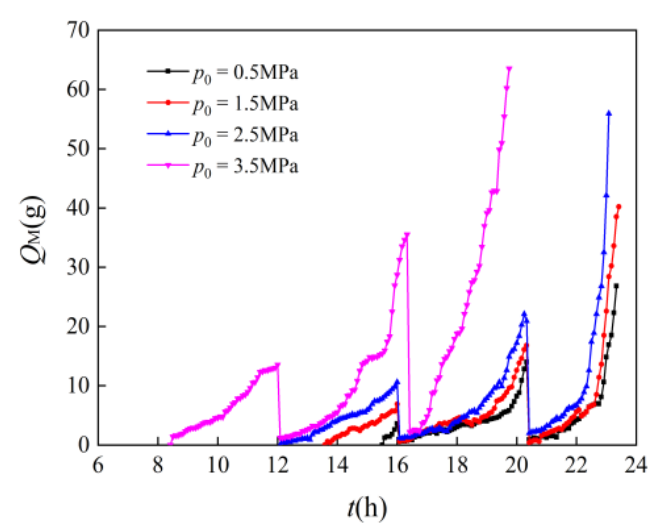

(a) Permeable capacity $Q_{\mathrm{M}}$

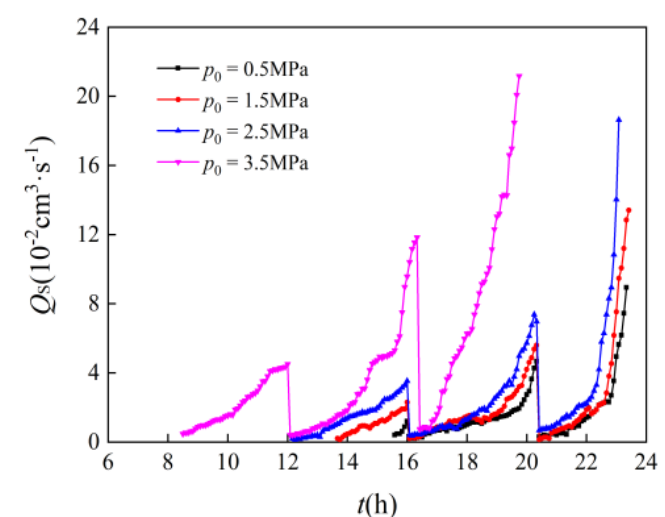

(b) Permeation rate $Q s$

Figure 16. Change of permeability of sandstone with seepage pressure.

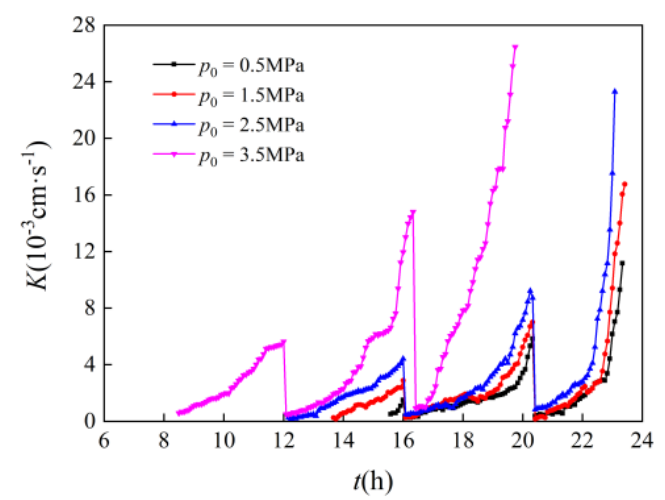

(a) Osmotic coefficient $K$

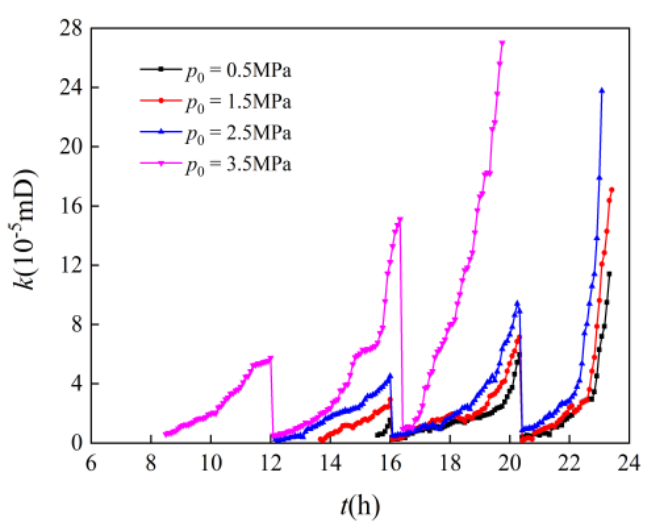

(b) Permeability $k$

Figure 17. Change of permeability parameters of sandstone with seepage pressure.

During the last variation period of sandstone permeability parameters (Figure 17), the permeability parameters are generally divided into three changing processes. The first phase lasts from $20.38 \mathrm{~h}$ to around $20.70 \mathrm{~h}$. The permeability parameters are at a smaller level (about 100 times of the permeability parameter of sandstone under the natural state), and this process lasts about $20 \mathrm{~min}$. The second phase begins at $20.70 \mathrm{~h}$ and ends at approximately $23.31 \mathrm{~h}$. The permeability parameters increase in a straight line with a fixed slope over time, and as the seepage pressure increases, the slope of the line increases gradually, and the change time in this stage accounts for about $80 \%$ of the entire change period. The last phase starts at $23.31 \mathrm{~h}$ and stops until the end of the test. The sandstone permeability parameters increase rapidly and reach a maximum in a very short time during this period. In fact, the change in the permeability characteristics of the sandstones in these three stages reflects the three 
processes of sandstone creep deformation under the final loading level. During the decelerating creep stage, internal cracks in the sandstone were closed; the internal structure was in a relatively stable state, and the permeability characteristics were stable, resulting in the permeation rate remaining equable and at a relatively small level. During the stable creep stage, the internal cracks in the sandstone expanded steadily and the permeation parameters continued to increase. During the accelerated creep stage, the internal cracks of the sandstone rapidly expanded and macroscopic permeable channels were formed, which leaded to a rapid increase in the permeability properties of the sandstone and a greater amount of permeable water.

\subsection{Macroscopic and Microscopic Mechanism Study on Coal Measures Sandstone Rupture under Seepage-Creep Coupling}

\subsubsection{Macroscopic Characteristics of Sandstone Rupture}

Figure 18 shows the macroscopic morphology after the creep failure of sandstone under different seepage pressures. Generally speaking, under the same confining pressure, the number of through cracks on the surface of specimens after creep failure increases with the increase of seepage pressure, indicating that the degree of macroscopic damage gradually increases.

When the seepage pressure is $0.5 \mathrm{MPa}$, there is a main crack that runs through the surface of the specimen, and there are many small cracks that run parallel to the main crack. The failure mode is a typical shear failure. When the seepage pressure increases to $1.5 \mathrm{MPa}$, there are several macroscopic cracks penetrating the surface of the specimen after the creep failure, and the cracks are parallel to the axial loading direction of the specimen. It can be determined that the failure mode is pulling damage. When the seepage pressure rises to $2.5 \mathrm{MPa}$, multiple flaky pieces are peeled off from the surface of the specimen, and both shear stress and tensile stress appear on the failure surface. The creep failure mode of the specimen is the form of pulling damage and shear failure. When the seepage pressure is $3.5 \mathrm{MPa}$, there is a shear failure plane that penetrates the sample. After the shear failure, many fragments exist on the tensile rupture surface which is parallel to the axial loading direction. The shear failure and tensile failure constitute the failure mode of the specimen together.

According to the macroscopic damage characteristics of the specimens, we can see that the seepage pressure has a significant impact on the creep failure of sandstone. Especially when the seepage pressure reaches $2.5 \mathrm{MPa}$ or more, the seepage pressure would act directly on the fracture plane after a macroscopic shear failure plane appears on the specimen under the action of axial load, resulting in many macroscopic fracture planes appearing in the block below the existing shear fracture plane.

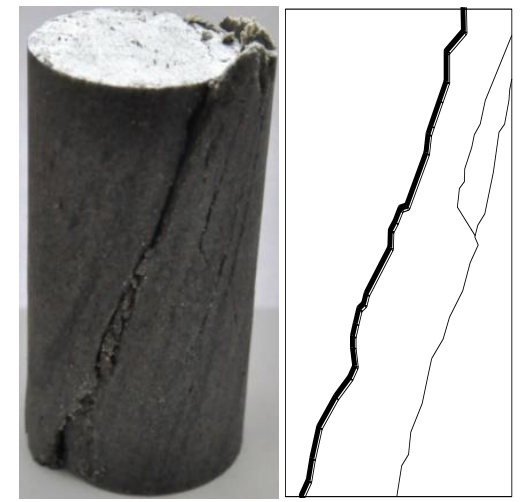

(a) $p_{0}=0.5 \mathrm{MPa}$

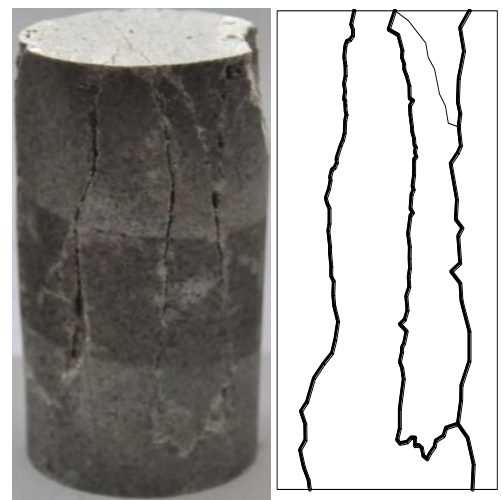

(b) $p_{0}=1.5 \mathrm{MPa}$

Figure 18. Cont. 


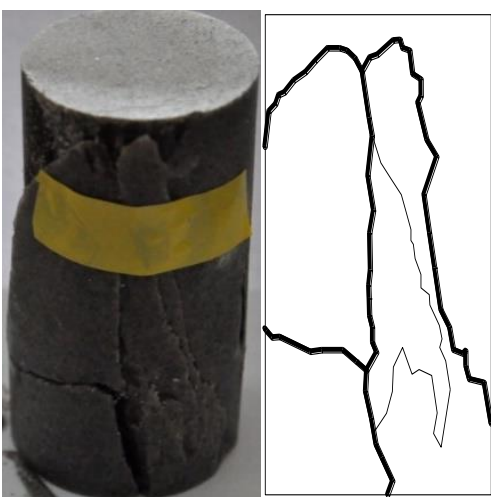

(c) $p_{0}=2.5 \mathrm{MPa}$

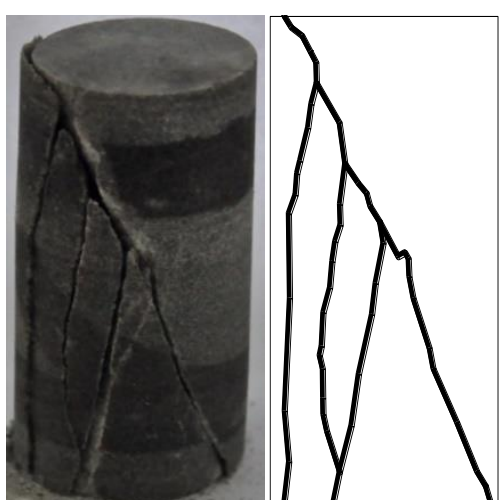

(d) $p_{0}=3.5 \mathrm{MPa}$

Figure 18. Creep failure characteristics of sandstone with different seepage pressures.

\subsubsection{Microscopic Characteristics of Sandstone Rupture}

Figures 19-22 show the observations of the fracture surface microscopic morphology of sandstones under different seepage pressures. It is obvious that the seepage pressure also has a significant effect on the micro-morphology of the sandstone creep failure.

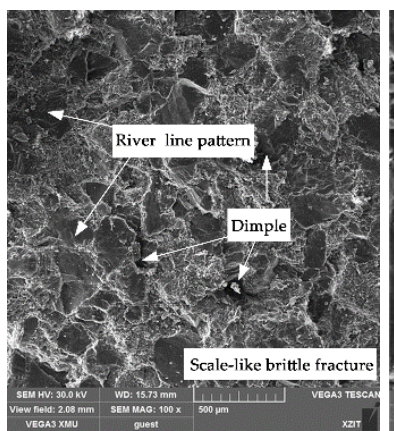

(a) $100 \times$

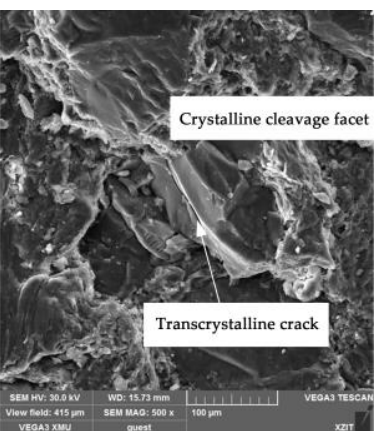

(b) $500 \times$

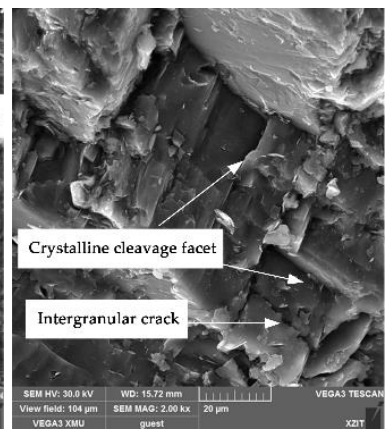

(c) $2000 \times$

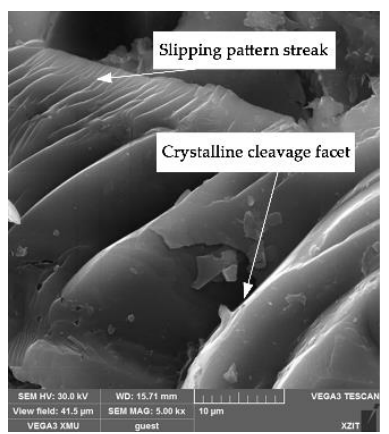

(d) $5000 \times$

Figure 19. Micro-morphology of sandstone fracture in creep under $p_{0}=0.5 \mathrm{MPa}$.

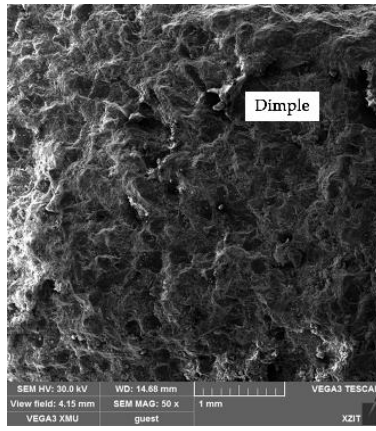

(a) $50 x$

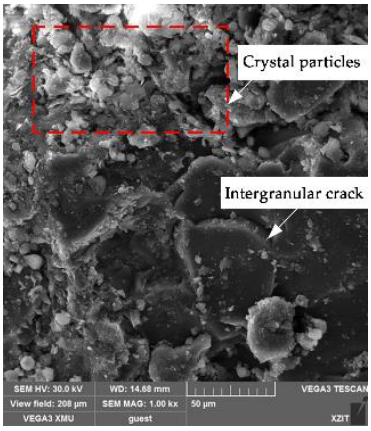

(b) $1000 \times$

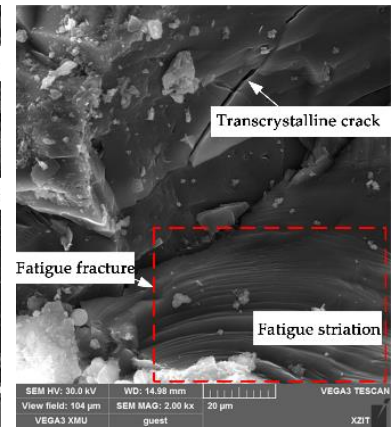

(c) $2000 \times$

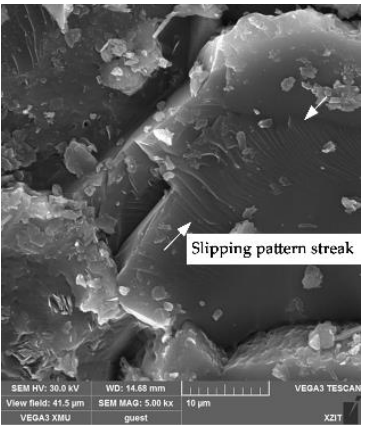

(d) $5000 \times$

Figure 20. Micro-morphology of sandstone fracture in creep under $p_{0}=1.5 \mathrm{MPa}$. 


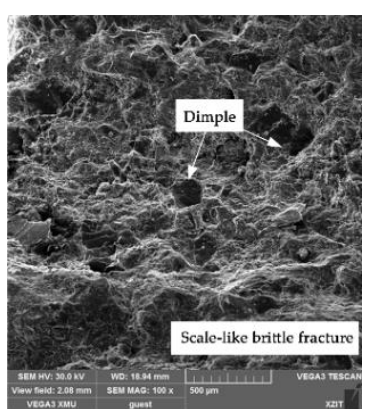

(a) $50 \times$

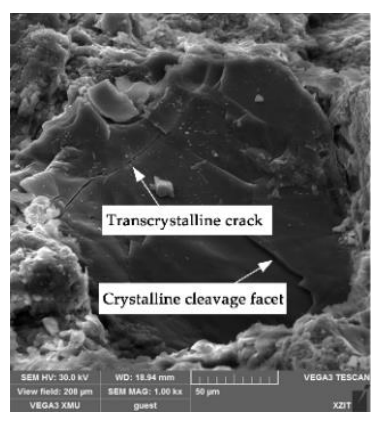

(b) $1000 \times$

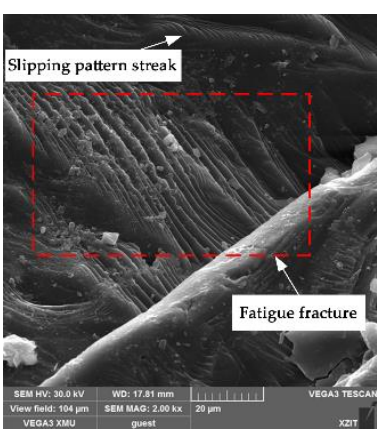

(c) $2000 \times$

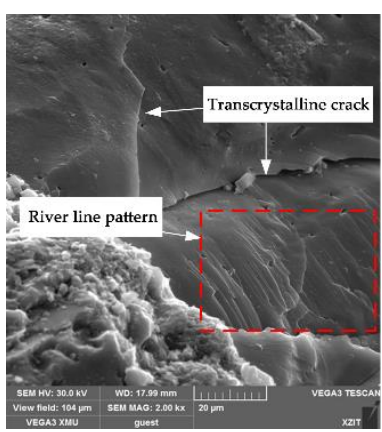

(d) $2000 \times$

Figure 21. Micro-morphology of sandstone fracture in creep under $p_{0}=2.5 \mathrm{MPa}$.

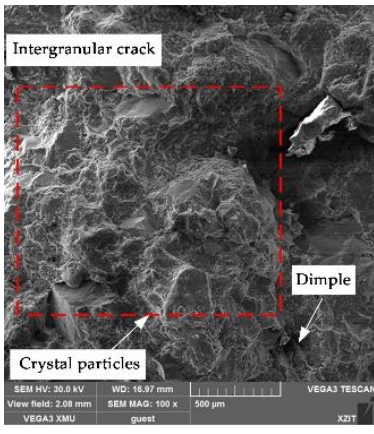

(a)100x

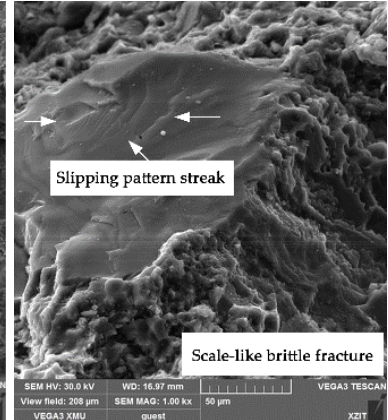

(b)1000x

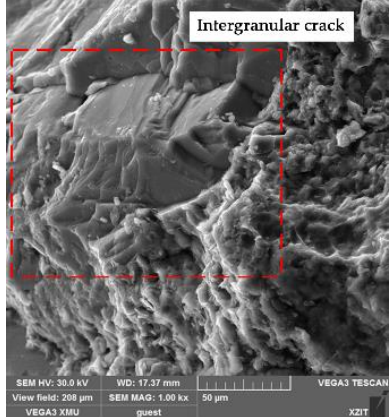

(c)1000×

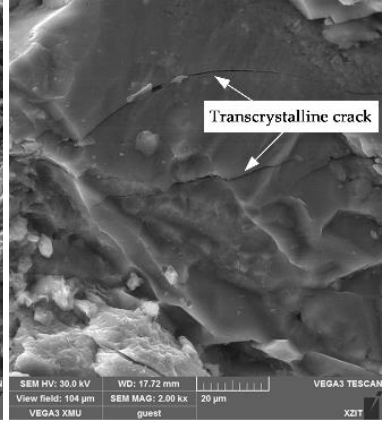

(d)2000×

Figure 22. Micro-morphology of sandstone fracture in creep under $p_{0}=3.5 \mathrm{MPa}$.

First, sandstone samples were observed with the SEM at 50/100 times magnification. Under the seepage pressure of $0.5 \mathrm{MPa}$ (Figure 19a), the fracture morphology of sandstone is dominated by river line pattern and scale-like brittle fracture, and there are sporadic dimples at the fracture. The fracture morphology of sandstone is mainly in the form of dimple under the seepage pressure of $1.5 \mathrm{MPa}$ (Figure 10a). When the seepage pressure increases to 2.5 MPa (Figure 21a) and 3.5 MPa (Figure 22a), brittle fractures such as scale-like brittle fracture and intergranular crack are abundantly present in the fractures of sandstone after creep failure. However, there are sporadic dimples locally. With the increase of seepage pressure, the microscopic mode of sandstone creep failure gradually changes from brittle fracture mode $\left(p_{0}=0.5 \mathrm{MPa}\right)$ to ductile fracture mode $\left(p_{0}=1.5 \mathrm{MPa}\right)$, and then to brittle fracture mode $\left(p_{0}=2.5,3.5 \mathrm{MPa}\right)$.

Next, the magnification of SEM was increased to 500/1000 times. Under the seepage pressure of $0.5 \mathrm{MPa}$ (Figure 19b), there is a significant crystalline cleavage facet in the fracture of sandstone. Many scale-like brittle fractures are distributed around the fracture and small transcrystalline cracks are spread over the fracture surface. When the seepage pressure becomes 1.5 MPa (Figure 20b), several large-scale transcrystalline cracks separate the crystal particles from each other and the brittle fracture characteristics are remarkable. There are some small transcrystalline cracks around the crystalline cleavage facet under the seepage pressure of $2.5 \mathrm{MPa}$ (Figure 21b). When the seepage pressure increases to $3.5 \mathrm{MPa}$ (Figure 22b,c), many scale-like brittle fractures are covered around the section and a small number of slipping patterns exist in the middle region. Generally, the microscopic mode of sandstone creep failure gradually changes from the brittle-ductile coupling fracture mode $\left(p_{0}=0.5 \mathrm{MPa}\right)$ to the single brittle fracture mode $\left(p_{0}=1.5 \mathrm{MPa}\right)$, and finally transforms into brittle-ductile coupling fracture mode again $\left(p_{0}=2.5,3.5 \mathrm{MPa}\right)$.

In the final step, sandstone samples were studied through the SEM at more than 2000 times magnification. When the seepage pressure is $0.5 \mathrm{MPa}$ (Figure 19c,d), the crystalline cleavage facets cover the surface of the fracture, and there are a set number of slipping pattern streaks in the local 
area. When the seepage pressure increases to $1.5 \mathrm{MPa}$ (Figure 20c,d), a new microscopic morphology appears on the fracture surface-fatigue fractures. A group of fatigue striations extend parallel to each other, and there are several significant transcrystalline cracks above the fatigue fracture surface. The fracture morphology of the sandstone under the seepage pressure of $2.5 \mathrm{MPa}$ is similar to that under the seepage pressure of $1.5 \mathrm{MPa}$ (Figure 21c,d). When the seepage pressure increases to $3.5 \mathrm{MPa}$ (Figure 22d), the fracture morphology of sandstone is relatively simple. Intergranular cracks become the main morphology of sandstone due to brittle failure, while there are some small transcrystalline cracks in the local area. In summary, as the seepage pressure increases step by step, the evolution of secondary microscopic fracture mode of sandstone creep failure is from brittle fracture $\left(p_{0}=0.5 \mathrm{MPa}\right)$ to fatigue fracture $\left(p_{0}=1.5,2.5 \mathrm{MPa}\right)$, and finally becomes brittle fracture $\left(p_{0}=3.5 \mathrm{MPa}\right)$. There are also several significant ductile fractures in some areas.

\subsubsection{Connection between Macroscopic and Microscopic Mechanism on Sandstone Rupture}

Under the influence of exterior load, the macroscopic failure of the rock is determined by the mesoscopic fracture of rock. The initiation, development, and connectivity of internal cracks in rock lead to local fractures. When the microscale damage and fracture accumulate to a certain extent, the macroscopic failure of the rock will occur.

With the increase of seepage pressure, the process of sandstone microscopic fracture mode evolves from low-energy brittle fracture $\left(p_{0}=0.5 \mathrm{MPa}\right)$ to moderate energy-consuming ductile fracture $\left(p_{0}=1.5 \mathrm{MPa}\right)$, and finally returns to low-energy brittle fracture $\left(p_{0}=2.5,3.5 \mathrm{MPa}\right)$. During the process of macroscopic deformation, the input energy of the sandstone sample is the same. When the energy consumption of microscopic fracture is low, the macroscopic failure mode of sandstone will inevitably lead to shear failure with low energy consumption, and the number of macroscopic fracture surfaces and the fracture degree are higher. On the other hand, when the energy consumption of microscopic fracture is higher, the macroscopic failure mode of sandstone becomes tensile failure, and the fracture degree will be lower. Therefore, after the creep failure of sandstone with seepage pressure $p_{0}$ of 0.5 , 2.5 , and $3.5 \mathrm{MPa}$, the failure mode of the samples is dominated by shear failure, and the number of macroscopic cracks on the surface of the samples is very large and the scale of the cracks is also larger. When the seepage pressure $p_{0}$ is $1.5 \mathrm{MPa}$, the typical pulling damage dominates the creep failure of the sandstone, and the number of macroscopic cracks on the surface of the samples is relatively less and the crack scale is also smaller.

\section{Conclusions}

This paper took the complete coal measures sandstone samples as the research object, and designed a rock seepage-creep coupling test system which is suitable for standard rock specimens. The creep tests under natural state and saturation state and the seepage-creep tests under different seepage pressures of coal measures sandstone were carried out. The effects of seepage pressure on the creep properties and permeability characteristics of sandstone were studied. By establishing the relationship between meso-fracture and macroscopic damage of sandstone, the mechanism of sandstone creep failure under seepage pressure is revealed. The main conclusions are as follows:

1. Based on the triaxial compression tests of coal measures sandstone, the creep tests of sandstone under natural and saturation state were carried out through the grading loading tests. The results showed that: The creep characteristic curves of sandstone in two conditions were the same, both including decelerating creep and steady creep at lower loading levels. When the loading level was higher, the creep curve included three complete processes: decelerating creep, isokinetic creep and accelerated creep.

2. The seepage pressure had a significant effect on the creep deformation and permeability characteristics of coal measures sandstone. When the confining pressure was invariant, the constant creep deformation rate and accelerated creep deformation rate of sandstone increased rapidly with the increase of seepage pressure. With the change of time, the change of sandstone 
permeability parameters underwent three cycles, and the characteristics of change in each cycle were also divided into two stages: slow change stage and rapid change stage. The change rate gradually increased with the increase of seepage pressure. As the permeation pressure increased, the permeation parameters measured for the first time gradually decreased accordingly.

3. When the confining pressure was invariant, with the increase of seepage pressure, the macroscopic damage of sandstone under natural and saturation conditions had a tendency of transition from tensile failure to shear failure. As the seepage pressure raised, the microscopic fracture mode of sandstone had changed from brittle fracture to ductile fracture and finally to brittle fracture. According to the macroscopic characteristics of sandstone rupture, microscopic morphology and fracture modes, the connection between macroscopic and microscopic mechanism on sandstone rupture was established.

In this article, we mainly used experimental methods to study the seepage-creep characteristics of coal measures sandstone, but the corresponding theoretical research still need to be continued. It is of urgent importance to establish a seepage-creep coupling model of coal measures sandstone based on the test results.

Author Contributions: Z.S., H.P., M.L. and L.C. conceived and designed the experiments; D.L., H.N. and J.L. performed the experiments; Z.S., M.L. and L.C. analyzed the data; H.P., D.L. and H.N. contributed analysis tools; Z.S., H.P., M.L. and L.C. wrote the paper.

Funding: This work was supported by the National Basic Research Program of China (2015 CB251601).

Acknowledgments: The authors are very grateful to the authors of all the references. The authors also express their gratitude to graduate students Xinghui Huo and Senhao Liu for their help in the revision of the paper.

Conflicts of Interest: The authors declare no conflict of interest.

\section{References}

1. He, M.; Jing, H.; Sun, X. Research progress of soft rock engineering geomechanics in china coal mine. J. Eng. Geol. 2000, 8, 46-62.

2. He, M. Engineering Mechanics of Soft Rock; Science Press: Beijing, China, 2002; pp. 52-109, ISBN 7-03-010340-8.

3. He, M.; Xie, H.; Peng, S.; Jiang, Y. Study on rock mechanics in deep mining engineering. Chin. J. Rock. Mech. Eng. 2005, 24, 2803-2813.

4. He, M. Conception system and evaluation indexes for deep engineering. Chin. J. Rock. Mech. Eng. 2005, 24, 2854-2858.

5. Zhou, H.; Xie, H.; Zuo, J. Research progress of rock mechanics behavior under deep high ground stress. Adv. Mech. 2005, 35, 91-99.

6. Xie, H.; Peng, S.; He, M. Basic Theory and Engineering Practice in Deep Mining; Science Press: Beijing, China, 2006; pp. 12-58, ISBN 7-03-016386-9.

7. Sun, J. Rock rheological mechanics and its advance in engineering applications. Chin. J. Rock. Mech. Eng. 2007, 26, 1081-1106.

8. He, F. The Research on Mechanism of Rock Creep-Seepage Coupling. Ph.D. Thesis, Liaoning Technical University, Fuxin, China, 2010.

9. Yang, H.; Xu, J.; Nie, W.; Peng, S. Experimental study on creep of rocks under step loading of seepage pressure. Chin. J. Geotech. Eng. 2015, 37, 1613-1619.

10. Griggs, D.T. Creep of Rocks. J. Geol. 1939, 37, 225-251. [CrossRef]

11. Wang, G. Advanced Rock Mechanics Theory; Metallurgical Industry Press: Beijing, China, 1996.

12. Zhou, W. Advanced Rock Mechanics; China Water \& Power Press: Beijing, China, 1990.

13. Maranini, E.; Brignoli, M. Creep behavior of a weak rock: Experimental characterization. Int. J. Rock. Mech. Min. 1999, 36, 127-138. [CrossRef]

14. Fan, Q.; Li, S.; Gao, Y. Experimental study on creep properties of soft rock under triaxial compression. Chin. J. Rock. Mech. Eng. 2007, 7, 1381-1385.

15. Chen, Y.; Sun, J. Rheological fracture characteristics of rock. Chin. J. Rock. Mech. Eng. 1996, 15, 20-24. [CrossRef] 
16. Li, J. Experimental study on the rheological shear properties of rock. Chin. J. Geotech. Eng. 2000, 3, $299-303$.

17. Zhang, Z.; Xu, W.; Zhao, H.; Jian, B. Investigation on shear creep experiments of sandstone with weak plane in xiangjiaba hydropower station. Chin. J. Rock. Mech. Eng. 2010, S2, 3693-3698.

18. Yang, G.; Xie, D.; Zhang, C.; Pu, Y. CT identification of rock damage properties. Chin. J. Rock. Mech. Eng. 1996, 15, 48-54.

19. Yang, G.; Lu, Z.; Pu, Y. The mechanic characteristics of damage propagation of rock under tri-axial stress condition. J. Xi'an Univ. Sci. Technol. 2000, 20, 101-104.

20. Ge, X.; Ren, J.; Pu, Y.; Ma, W.; Zhu, Y. A real-in-time CT triaxial testing study of meso-damage evolution law of coal. Chin. J. Rock. Mech. Eng. 1999, 18, 497-502.

21. Ge, X.; Ren, J. Study on the real intime CT test of the rock meso-damage. Sci. China 1999, 2, 104-111.

22. Cao, S.; Liu, Y.; Zhang, L.; Jiang, Y. Experimental on acoustic emission of outburst-hazardous coal under uniaxial compression and creep. J. China Coal. Soc. 2007, 32, 1264-1268.

23. Chen, W.; Zhao, F.; Gong, H. Study of triaxial creep mechanism of mica-quartz schist based on microscopic test. Chin. J. Rock. Mech. Eng. 2010, 29, 3578-3584.

24. Zhang, Q.; Yang, W.; Chen, F.; Li, W.; Wang, J. Long-term strength and microscopic failure mechanism of hard brittle rocks. Chin. J. Geotech. Eng. 2011, 33, 1910-1918.

25. Louis, C. Rock Hydraulics in Rock Mechanics; Springer Vienna: New York, NY, USA, 1974; pp. 36-108.

26. Jones, F.O. A laboratory study of the effects of confining pressure on fracture flow andstorage capacity in carbonate rocks. J. Pet. Technol. 1975, 27, 21-27. [CrossRef]

27. Nelson, R.A. Fracture Permeability in Porous Reservoirs: An Experimental and Field Approach. Ph.D. Thesis, Texas A\&M University, College Station, TX, USA, 1975.

28. Kranz, R.L.; Frankel, A.D.; Engelder, T. The permeability of whole and jointed Barre granite. Int. J. Rock. Mech. Min. 1979, 16, 225-234. [CrossRef]

29. Gale, J.E. The effects of fracture type (induced versus natural) on the stress-fracture closure-fracture permeability relationships. In Proceedings of the 23rd U.S Symposium on Rock Mechanics (USRMS), Berkeley, CA, USA, 25-27 August 1982.

30. Iwai, K. Fundamental Studies of Fluid Flow through a Single Fracture. Ph.D. Thesis, University of California, Oakland, CA, USA, 1976.

31. Mordecai, M.; Morris, L.H. An investigation into the changes of permeability occurring in a sandstone when failed under triaxial stress conditions. In Proceedings of the 12th U.S. Symposium on Rock Mechanics (USRMS), Rolla, MI, USA, 16-18 November 1970.

32. Li, S.; Chen, Z.; Miao, X.; Liu, Y. Experimental study on the properties of time-dependent deformationseepage in water-saturated broken sandstone. J. Min. Saf. Eng. 2011, 28, 542-547.

33. Miao, X.; Li, S.; Chen, Z.; Liu, W. Experimental study of seepage properties of broken sandstone under different porosities. Transp. Porous Med. 2011, 86, 805-814. [CrossRef]

34. He, F.; Wang, L.; Wang, Z.; Yao, Z. Experimental study on creep seepage coupling law of coal (rock). J. China Coal. Soc. 2011, 36, 930-933.

35. Zhu, Z.; Xu, W.; Zhang, A. Mechanism analysis and testing study on Damage and fracture of brittle rock. Chin. J. Rock. Mech. Eng. 2003, 22, 1411-1416.

36. Zhang, S.; Cox, S.F.; Paterson, M.S. The influence of room temperature deformation on porosity and permeability in calcite aggregates. J. Geophys. Res. 1994, 99, 15761-15775. [CrossRef]

37. Liu, R.; Li, B.; Jiang, Y. A fractal model based on a new governing equation of fluid flow in fractures for characterizing hydraulic properties of rock fracture networks. Comput. Geotech. 2016, 75, 57-68. [CrossRef]

38. Li, B.; Liu, R.; Jiang, Y. Influences of hydraulic gradient, surface roughness, intersecting angle, and scale effect on nonlinear flow behavior at single fracture intersections. J. Hydrol. 2016, 538, 440-453. [CrossRef]

39. Yang, T.; Tang, C.; Zhu, W.; Feng, Q. Coupling analysis of seepage and stresses in rock failure process. Chin. J. Geotech. Eng. 2001, 23, 489-493.

40. Pu, H.; Cao, L.; Qiu, Y.; Qiu, P. Study of overlying strata creep affected by seepage in backfilling mining process. J. Min. Saf. Eng. 2015, 32, 846-852.

41. Souley, M.; Homand, F.; Pepa, S.; Hoxha, D. Damage-induced permeability changes in granite: A case example at the URL in Canada. Int. J. Rock. Mech. Min. 2001, 38, 297-310. [CrossRef]

42. Ma, D. Water-Rock-Sand Mixture Flow Theory of Crushed Rocks and Temporal-Spatial Evolution. Ph.D. Thesis, China University of Mining and Technology, Xuzhou, China, 2017. 
43. Yao, B. Research on Variable Mass Fluid-Solid Coupling Dynamic Theory of Broken Rock Mass and Application. Ph.D. Thesis, China University of Mining and Technology, Xuzhou, China, 2012.

44. Wang, L. Accelerated Experimental Study on Permeability for Broken Mudstone with Mass Loss. Ph.D. Thesis, China University of Mining and Technology, Xuzhou, China, 2014.

45. Yan, Y. Research on Rock Creep Tests under Seepage Flow and Variable Parameters Creep Equation. Ph.D. Thesis, Tsinghua University, Beijing, China, 2009.

46. Li, Y.; Ma, Z.; He, Y.; Wang, B.; Liang, X. Experimental Research on Permeability of Rocks of Coal-Bearing Strata. J. Exp. Mech. 2006, 21, 129-134. [CrossRef]

(C) 2018 by the authors. Licensee MDPI, Basel, Switzerland. This article is an open access article distributed under the terms and conditions of the Creative Commons Attribution (CC BY) license (http://creativecommons.org/licenses/by/4.0/). 